\title{
EVALUATION OF A NEW SUSTAINABLE CONTINUOUS SYSTEM FOR PROCESSING BOVINE LEATHER
}

Anna Bacardit, Grau Baquero, Silvia Sorolla, Luis Ollé

\author{
$\mathrm{A}^{3}$ Chair in Leather Innovation. Escola d'Enginyeria d'Igualada (EEI). Universitat Politècnica de \\ Catalunya $(U P C)$ \\ Pla de la Massa,8. 08700 Igualada, Spain
}

\begin{abstract}
The aim of the present work is to evaluate a new sustainable continuous system for processing bovine leather. By means of a prototype described in the international patent WO 2010/070571 (A2) of the technological centre AIICA, a dehydration process for bovine hides is carried out. What is obtained through this new process is a dehydrated leather with the optimal physical and chemical characteristics that will allow its subsequent tanning by immersion processes in aqueous solutions of chemical products. When compared to existing traditional processes, there are economic and environmental advantages resulting from the use of this new system. More specifically, the new process results in reductions of $30.6 \%$ in water use, $50.2 \%$ in chemical use and $16.4 \%$ in process time. In addition, a reduction of $27.3 \%$ in wastewater and a reduction of $47.5 \%$ of thermal energy consumption are obtained. However, this new system presents an increase in electricity consumption of $63.03 \%$ and an increase in gaseous emissions of $75 \%$ due to the use of acetone in the dehydration process and the $0.5 \%$ losses of acetone during the process.

In order to better assess the environmental impact of this new tanning system, life cycle analysis methodology has been chosen to perform calculations on the global warming potential $\left(\mathrm{CO}_{2}\right.$ equivalent emissions) and the energy consumption comparing both traditional and new tanning processes.
\end{abstract}

\section{Keywords}

Dehydration; leather; tannage; global warming potential

\section{Introduction}

The chrome tanning method is the most widely used and represents the $90 \%$ of world production, thanks to its ease of use and good properties given to the skin: durability, hydrothermal resistance, touch, fullness, etc. However, the use of chromium is a controversial issue because of its toxicity and persistence in the environment that represent some of its chemical forms. 
A great variety of projects have been carried out in order to minimize this impact: recycling of pickletanning floats (Morera et al., 2011), recovery and treatment of chrome floats (Kanagaraj et al., 2008), high exhaustion of such floats (Bacardit et al., 2008; Thanikaivelan et al., 2004; Legesse et al., 2002), management of solid waste containing chrome (Hu et al., 2011), and the use of other tanning agents to substitute chrome (Ollé et al., 2001; Saravanabhavan et al., 2003; Taylor et al., 2011).

The present work is based on the knowledge acquired in two previous studies (AIICA, 2010; Ollé et al.; 2013a; Ollé et al., 2013b). In these mentioned studies_a prototype to obtain a new collagenic material by dehydration was developed and -the best process for obtaining dehydrated bovine hides was studied. Once the optimum process was established, a dehydration system for bovine hide at industrial stage was designed, which allows for a dry and very porous substrate to be obtained, which facilitates the application of tanning agents, dyes and fats by immersion in aqueous solutions.

Indeed, dehydration technologies based on the use of solvents have been developed since the beginning of the twentieth century. However, a proper system for the recovery of the solvent used is yet to be determined. Also, futher research is needed to determine whether the dehydrated hide is in the optimum condition to be subsequently stabilized and transformed into finished leather ( Teliba et al., 1993; Chagne et al., 1993, Silvestre et al., 1994).

In the present work, a process of tanning by immersion of dehydrated bovine leathers with the aim of minimizing the negative effect of the tanning pollution was studied. Specifically, the processing of $1000 \mathrm{~kg}$ of raw salted hide generates approximately $22 \mathrm{~m}^{3}$ of residual effluent with high concentrations of pollutants, plus approximately $730 \mathrm{~kg}$ of solid waste and $40 \mathrm{~kg}$ of emissions. Another parameter to take into consideration is the low efficiency of the chemical processes which take place during the process of tanning. An excess of tanning products is needed in order to stabilize $1000 \mathrm{~kg}$ of raw hide, that is, approximately $60 \mathrm{~kg}$ of chrome salts or more than $450 \mathrm{~kg}$ of vegetable extracts (European IPPC Bureau, 2009; International Union Environment of IULTCS, 2008).

It is expected through the design of the new continuous system to obtain a reduction of the process time, a reduction of the chemicals used and a reduction of the water consumption compared to those of the conventional process.

\section{Material and methods}




\subsection{Material}

The tests were carried out using hides splits at $2.5 \mathrm{~mm}$. In order to finish the preparation before dehydration, the hides were delimed using $1.5 \%$ of a commercially available carboxylic acid and were bated using $0.7 \%$ of enzymes of $1000 \mathrm{LVU} / \mathrm{g}^{-1}$. The $\mathrm{pH}$ of the hides is 8.5 ; the hides are negatively charged since the ionised groups of collagen in this $\mathrm{pH}$ are carboxyl groups. In order to reach the isoelectric point of the hide, a neutralisation has to be carried out using $0.5 \%$ of formic acid, correcting the $\mathrm{pH}$ with $\mathrm{NaHCO}_{3}$ if it goes below 5.0. The $\mathrm{pH}$ obtained is 5-5.5, which is the point at which the ionisation of the pelts is the lowest. In this condition, the water present in the hide =pelt is less likely to create hydrogen bonds and it is then easier to move the water towards the external medium of solution.

\subsection{Dehydration process}

The prototype consists of a wash drum, two collection tanks for the final floats, a tank to recover the condensated solvent and a tank for feeding solvent. As for the recovery of acetone in the final floats, a distiller is coupled to a cooling tower, which also collects the recovered gas emissions. The prototype is made of stainless steel and is appropriately equipped with pumps and valves for the processing of solvents. Fig. 1 shows the prototype as seen from different perspectives. And Fig. 2 shows a picture of the prototype.

Next is a brief description of the units in prototype (1):

-Stainless steel machine (2) with wash drum (2a) with variable rotation speed, of $360 \mathrm{~L}$ capacity.

Pneumatic valves, full automation of wash process times and subsequent spin cycles to replace the sammying operation. The final floats are collected by the different tanks of the device depending on the concentration of acetone.

-Distillation column (3) to separate the solvent from the rest of the float (fat + water + leather fibres + $\underline{\text { dissolved salts) }}$

\section{-Condensation unit (6) with a cooling system}

-Tank to collect the final floats (4) comprised of different compartments: (4a) tank to collect the solvent condensed during the process of acetone distillation; (4b) collection of centrifugation float and sammying float; (4c) collection of the last wash float with solvent to recirculate it through a first float application; 4(d) feed tank

-Heating units (7) and (9) 
-Circulation nozzle (5) of final wash float with acetone

- Nozzle (5a) to circulate the final recovery wash float into the system

- Drum solvent feed nozzle (8)

- Nozzle (10) to circulate solvent vapours into the condensation unit

The working parameters for bovine hides into the prototype are described in Table 1.

Formatted: English (U.S.)

\subsection{Tanning and post-tanning by immersion of dehydrated hides}

In this stage, a tanning and post-tanning processes on dehydrated pelts were carried out by means of a roller machine at industrial scale as it can be seen in Fig. 3.

A solution of $10 \%$ of chromium salt with a basicity of $45^{\circ} \mathrm{Sch}$ is prepared. The solution is deposited in the immersion compartment of the roller machine. The speed of the rollers is $4.4 \mathrm{~m} / \mathrm{mm}$ and the speed of the conveyor is $3.3 \mathrm{~m} / \mathrm{mm}$. The process time of tanning by immersion is 13 seconds. In order to obtain a good tannage, two applications were performed.

After tannage, a solution is prepared with $10 \%$ of synthetic retanning product, $2 \%$ of dyestuff, $3 \%$ of soya lecithin, $2 \%$ of sulfonated beef tallow and $4 \%$ of oxisulfated marine oil. The solution is deposited in the immersion compartment of the roller machine. The speed of the rollers is $4.4 \mathrm{~m} / \mathrm{mm}$ and the speed of the conveyor is $3.3 \mathrm{~m} / \mathrm{mm}$. The process time of post-tanning by immersion is 13 seconds. In order to obtain a good post-tannage, two applications are performed.

Once the tannage and post-tannage by immersion is finished, the hides are dried for 12-14 hours.

\subsection{Characterization of the leathers obtained}

The following tests were carried out on the teather batch that has been dehydrated, tanned and post-tanned through immersion and finished:

-IUP 6. Measurement of tensile strength and percentage elongation. Correspondence with ISO 3376:2002.

-IUP 8. Measurement of tear load. Correspondence with ISO 3377-2:2002.

-IUP 9. Measurement of distension and strength of grain by the ball burst test. Correspondence with ISO 3379:1976. 
-IUP 16. Measurement of shrinkage temperature. Correspondence with ISO 3380:2002.

-IUP 20. Determination of flex resistance. Correspondence with ISO 5402-1:2002.

-IUF 450. Colour fastness to cycles of to-and-fro rubbing. Correspondence with EN ISO 11640.

-IUF 470. Leather-Test for adhesion finish. Correspondence with ISO 11644:2009.

-IUC 4. Determination of matter soluble in dichloromethane. Correspondence with ISO 4048:2008.

-IUC 6. Determination of water soluble matter, water soluble inorganic matter, and water soluble organic matter. Correspondence with ISO 4098:2006.

-IUC 8. Determination of chromium oxide content. Correspondence with ISO 5398-1:2007.

-IUC -11. Determination of $\mathrm{pH}$ and difference figure. Correspondence with EN ISO 4045.

The proposed new system as well as the traditional tanning system stages are shown in Fig. 4.

\subsection{Analysis of the environmental impact}

In order to carry out a study of the feasibility of the new system, a basic material and energy balance calculation was performed. More specifically, water supply, chemical products consumption, electricity and thermal energy consumption, solid wastes and wastewater obtained, as well as gaseous emissions were compared.

Apart from the basic material and energy balance calculation, life cycle analysis (LCA) methodology has been chosen to perform a more reliable and quantifiable environmental comparison between both traditional and new tanning process. In order to achieve this goal, calculations on the global warming potential (GWP) and the energy consumption comparing both production systems are presented in this work.

LCA is a recognized tool to-make decisions, since it allows evaluating the environmental impact of a particular management system. It also allows comparing its impact with those of other management systems. LCA methodology is regulated by the ISO 14040 and 14044 (ISO-14040, 2006; ISO-14044; 2006) international standards. The GaBi 4 software from PE International (PE International, 2009) has been used to perform this LCA analysis.

In comparison with the basic material and energy balances, LCA approach takes also into consideration the production of the chemicals used as well as the emissions they generate. This wider view of the process, allows a more detailed environmental evaluation, quantitatively measuring the effect of the chemicals and energy used. 


\section{Results and discussion}

\subsection{Characterization of the leathers obtained}

The aim at this stage is to assess whether the leathers processed with this new system present better properties than the traditional ones. Table 3 shows the physical and chemical tests carried out on the tanned leathers.

As can be seen in Table 3, leathers tanned with the new system gave similar results like those for the traditional one. Dehydrated leathers showed slightly lower values in shrinkage temperature but present high values in tensile strength (IUP 6) and in tear load (IUP 8). This is due to the fact tehat the dehydration process, confers to the hide a rubbery state.

\subsection{Analysis of the environmental impact}

The aim of the second part of this study is to assess whether the dehydrated hides at industrial level and tanned and post-tanned by immersion presents an environmental advantage versus the traditional one, that is if using this new system a reduction of process water, chemicals and process time can be obtained.

The subsequent figures present the basic material and energy balance calculation, i.e. in water (Fig. 5), chemical use (Fig. 6), process time (Fig. 7), electricity consumption (Fig. 8) and thermal energy (Fig. 9).

As can be seen in the process flow Echart (Fig. 4), the dehydration process consists in removing water content from the neutralised leather in order to obtain a dry and porous collagen substrate. It is through this process that products by immersion can be applied. These new immersion processes allow the chemical products to readily diffuse in such a manner that the subsequent processes will be shorter when compared to the traditional process, also requiring less chemicals and amount of water (see Fig. 5,6 and 7).

Fig. 5 shows that the main reduction in water use is obtained during the pickling, tannage and posttannage processes as these are not required in the new system. A total reduction in water consumption of $30.6 \%$ is obtained.

Fig. 6 shows that the main reductions in chemical use are obtained once again during the processes of pickling, tannage and post-tannage according to the new proposed system. Chemical use is reduced by 
$50.2 \%$.

Fig. 7 shows that the main reduction in process time is once again obtained during the processes of pickling, tannage and post-tannage. Process time is reduced by $16.4 \%$.

Fig. 8 shows the comparison in electricity consumption. Electricity consumption is increased by $63.03 \%$. As can be seen, the main disadvantage of the new system is the high electrical energy consumption in the dehydration; this is due to the $5 \%$ of losses in acetone. This is a parameter that has to be improved in further investigations.

Fig. 9 shows thermal energy consumption in the new system, more specifically, a reduction by $47.5 \%$ is produced. This improvement in thermal energy consumption is due to the tannage and post-tannage by immersion in which the drying is shorter.

In addition, a balance in wastes was performed, i.e. in solid wastes, in wastewater, and gaseous emissions.

There is no significant reduction in production of solid waste. However, it must be taken into account that the production of dehydrated waste from shavings and trimmings of dehydrated leather is different from that of the conventional process since it doesn't contain any chrome and can be reused as collagen.

The production of waste water is reduced by $27.8 \%$. Although with the new system an increase of $75 \%$ in gaseous emissions is obtained. Thishe cause of this increase is due to the use of acetone and its $0.5 \%$ loss of during dehydration.

\subsection{Analysis of the environmental impact according to Life Cycle Analysis methodology}

Based on LCA methodology, GWP and energy consumption are calculated in this work to environmentally compare the traditional and proposed tanning systems.

Comparative results for GWP and energy consumption are shown in Figure 10, showing a clear preference for the proposed system for GWP whereas better results for the traditional system for energy consumption.

Reduction of GWP was expected according to the material and energy balances presented. However, higher energy consumption in the new system has not been presented in the basic energy balance, where conversely, a reduction in the new process energy consumption has been detected. The acetone 
production is the cause of this GWP results, being acetone the major contributor to energy consumption in the new tanning process, thus, a sensitivity analysis on this particular chemical is needed to assess its effect to the results.

Fig. 11 shows the contribution of acetone to GWP and also to energy consumption of the proposed system. Acetone production is clearly the responsible for the high energy consumption in the new tanning process.

According to these results, a reduction in the use of acetone during the process will affect positively on the results. In the current results, a $5 \%$ loss for each of the 5 baths with acetones is considered. If the $5 \%$ acetone losses of the prototype used could be reduced to a $2 \%$, the energy consumption of the new process would be slightly lower than the one of the traditional process. At the same time, this reduction would make the GWP even lower; lowering the $\mathrm{CO}_{2}$ equivalent emissions from the initial $27 \%$ reduction to a $57 \%$ reduction (see Fig. 12). This proposal should be achieved by the improvement of the prototype, mainly its sealing and the inlet and outlet circuits.

\section{Conclusions}

The dehydrated hides can be transformed into stabilised leather by immersing the hides in an aqueous solution of chemical products after a short period of application.

The quality and the properties of the leathers manufactured with the new system are similar to those obtained with the traditional one.

When assessing the environmental impact of the new system, consumption of chemical products, water and process time with the new system in respect to the conventional process, there are reductions of $30.6 \%$ in water use, $50.2 \%$ in chemical use and $16.4 \%$ in process time. In addition, a reduction of $27.3 \%$ in wastewater and a reduction of $47.5 \%$ of thermal energy consumption are obtained. However, this new system presents an increase in electricity consumption of $63.03 \%$ and an increase in gaseous emissions of $75 \%$ due to the use of acetone in the dehydration process and the $0.5 \%$ losses of acetone during the process. Based on these results, the proposals of improvements in the prototype have been presented to reduce the losses of acetone during the process.

LCA-based environmental evaluation show better results for GWP in the new proposed system compared to traditional tanning process. However, energy consumption is higher in the new tanning process due to the acetone losses detected in the prototype used in the tanning tests. A reduction in the acetone losses would lower the energy consumption impact from the new system to the level of the traditional system. A further reduction in the acetone losses would clearly make the proposed tanning process energetically preferable to the traditional system. 


\section{Acknowledgments}

The contents of this paper are part of the "Dermagenesis" Project funded by the EU (COLL-CT-2003$\left.500224-2,6^{\text {th }} \mathrm{FP}\right)$.

\section{References}

Bacardit, A.; Morera, J.M.; Ollé, L.; Bartolí, E.; Borràs, M.D., 2008. High chrome exhaustion in a non-float tanning process using a sulphonic aromatic acid. Chemosphere, 73(5), 820-4.

Chagne, V., Silvestre, F., Gaset, A, 1993. New tanning process in a water immiscible organic solvent medium: Use of chrome tanning materials with automatic basification, J. Am. Leather Chem. Assoc., $88,12,426-439$.

European IPPC Bureau, 2009. IPPC, First Draft Reference Document on Best available Techniques in the Tanning of Hides and Skins, Draft 27 of February 2009, EC, Competitiveness and Sustainability Unit.

Hu, J., Xiao, Z., Zhou, R., Deng, W., Wang, M., 2011. Ecological utilization of leather tannery waste with circular economy model, Journal of Cleaner Production, 19 (2-3), 221-228.

International Union Environment of the IULTCS, 2008. IUE 6: Pollution values from tannery processes under conditions of good practice.

ISO-14040. Environmental Manangement Life Cycle Assessment Principles and framework. Geneve: International Organization for Standardization (ISO); 2006.

ISO-14044. Environmental Manangement Life Cycle Assessment Requirements and guidelines. Geneve: International Organization for Standardization (ISO); 2006.

Kanagaraj, J., Chandra Babu, N.K., Mandal, A.B., 2008. Recovery and reuse of chromium from chrome tanning waste water aiming towards zero discharge of pollution, Journal of Cleaner Production, 16 (16), 1807-1813.

Legesse, W.; Thanikaivelan, P.; Rao, J. Raghava; Unni Nair, Balachandran, 2002. Underlying principles in chrome tanning: Part 1. Conceptual design of pickle-less tanning. J. Am. Leather Chem. Assoc., 97(12), 475-486. 
Ollé, L., Jorba, M., Font, J., Shendrik, A., Bacardit, A., 2011. Biodegradation of wet-white leather. J. Soc. Leather Tech. Chem., 95, 116.

Ollé, L., Sorolla, S., Casas, C., Bacardit, A., 2013. Design of a prototype to obtain a new collagenic material by dehydration. J. Soc. Leather Tech. Chem., 77,174.

Ollé, L., Sorolla, S., Casas, C., Bacardit, A., 2013. Design of a dehydration process for bovine leather to obtain a new collagenous material. Journal of cleaner production,

http://dx.doi.org/10.1016/j.jclepro.2013.01.044

PE INTERNATIONAL. GaBi Software. Leinfelden-Echterdingen: Institut für kunststoffprüfung und Kunststoffkunde; 2009.

Saravanabhavan, S. Aravindhan, R., Thanilaivelan, P., Chandrasekaran, B., Rao, J.R., Nair, B.U., 2003. An integrated eco-friendly tanning method for the manufacture of upper leather from goatskins. J. Soc. Leather Tech. Chem., 87, 149.

Silvestre, F., Rocrelle, C., Gaset, A., 1994. Clean technology for tannage with chromium salts. Part 1. Development of a new process in hydrophobic organic solvent media, J. Am. Leather Chem. Assoc.,78, 1, 1-17.

Taylor, M.M., Lee, J., Bumanlag, E., Hernandez Balada, E., Brown, E.M., 2011. Treatments to Enhance Properties of Chrome-free (Wet white) Leather. J. Am. Leather Chem. Assoc., 106, 2, 35-43. Teliba, B., Sibari, A., Silvestre, F., Gaset, A., 1993. Vegetable tanning in apolar solvent media, J. Soc. Leather Tech. Chem., 77,174.

Thanikaivelan, P., Rao, J.R., Nair, B.U., Ramasami, T. 2004. Underlying principles in chrome tanning: Part II. Underpinning mechanism in pickle-less tanning. J. Am. Leather Chem. Assoc., 99, 83.

WO 2010/070571 A2 -Procedure of the tanning of skins, material obtained during said procedure and device-. 
Figure 1
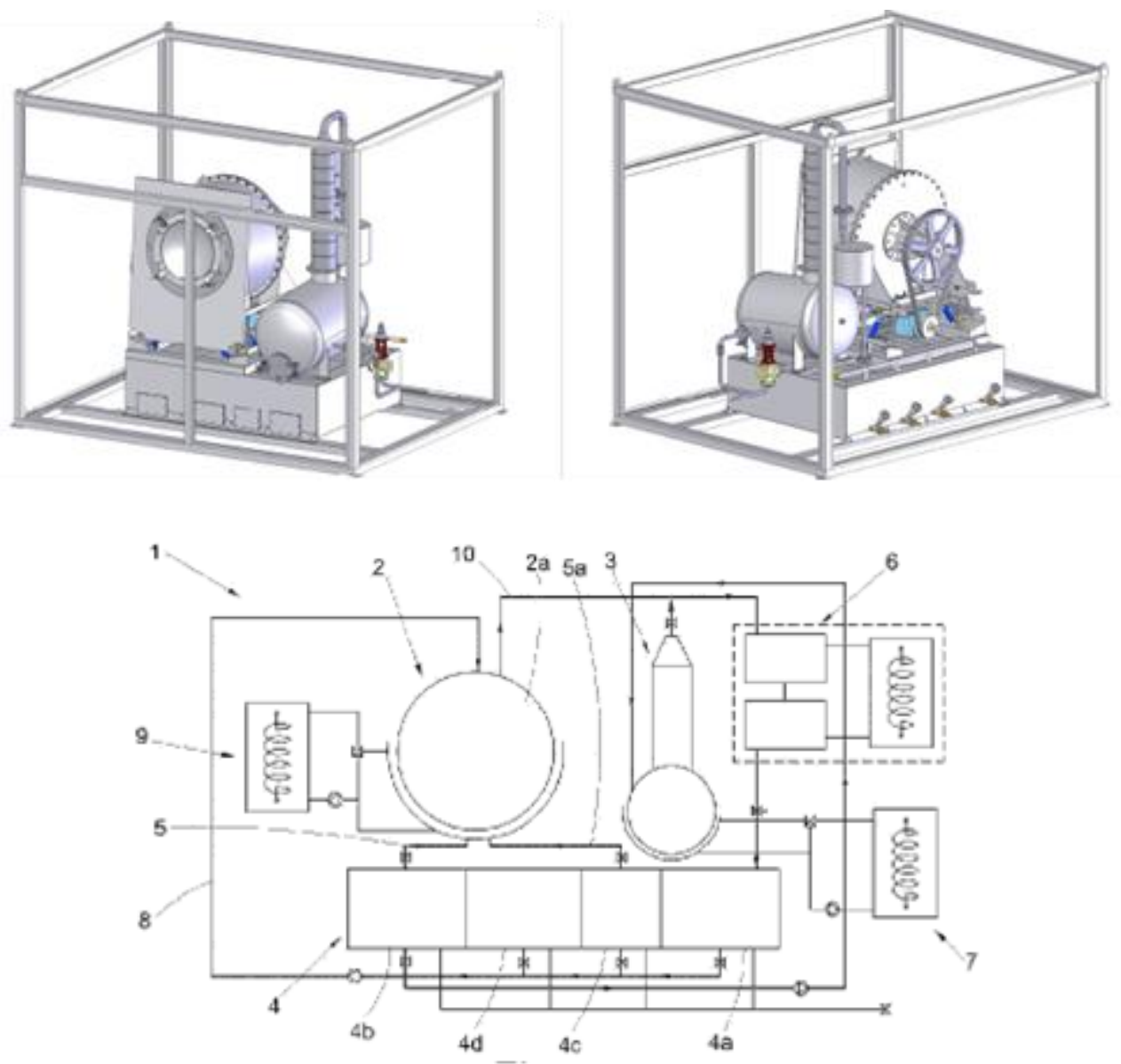


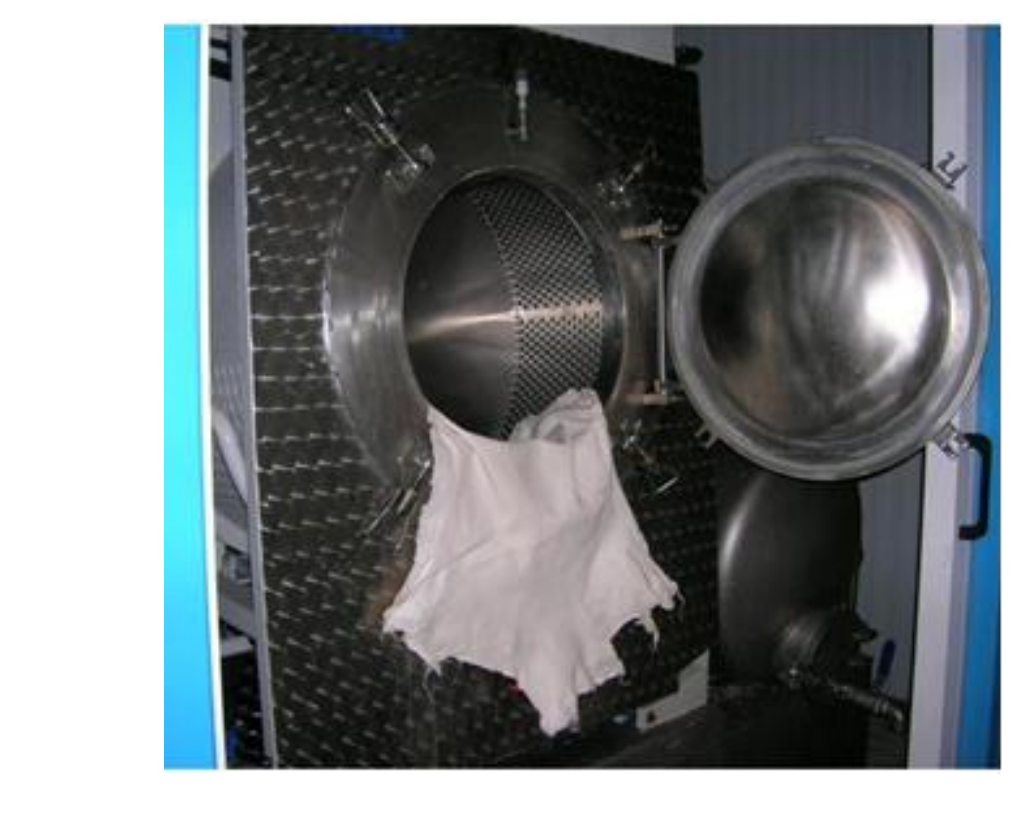

Figure 2

Figure 2

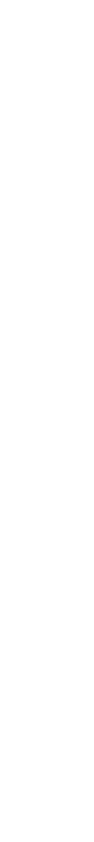

.
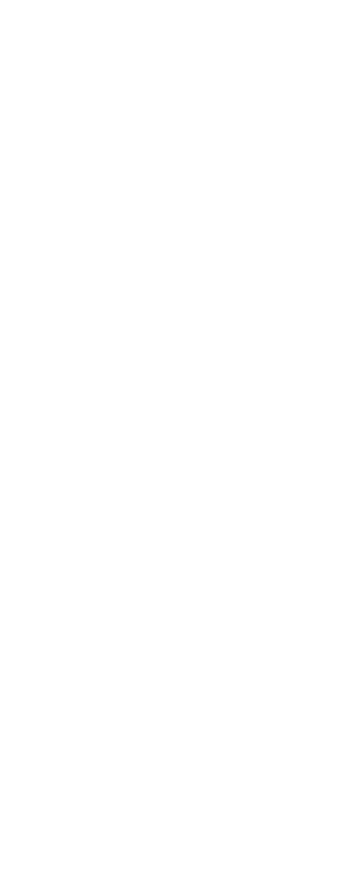

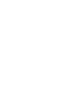

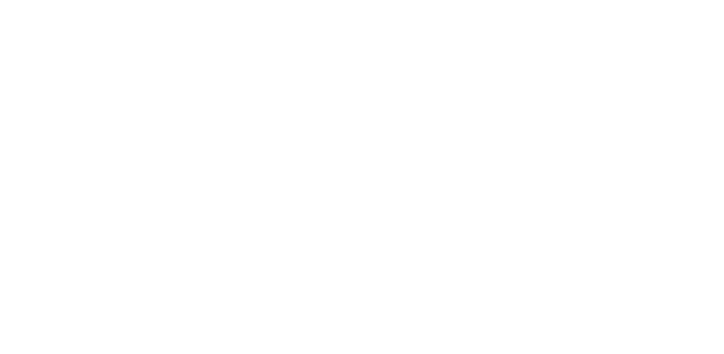

1
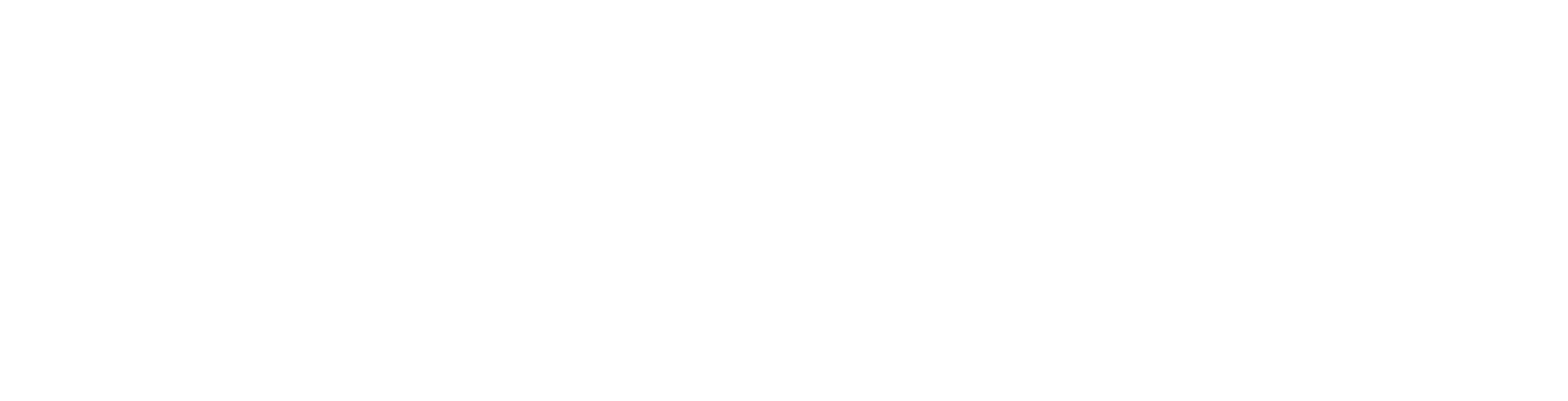

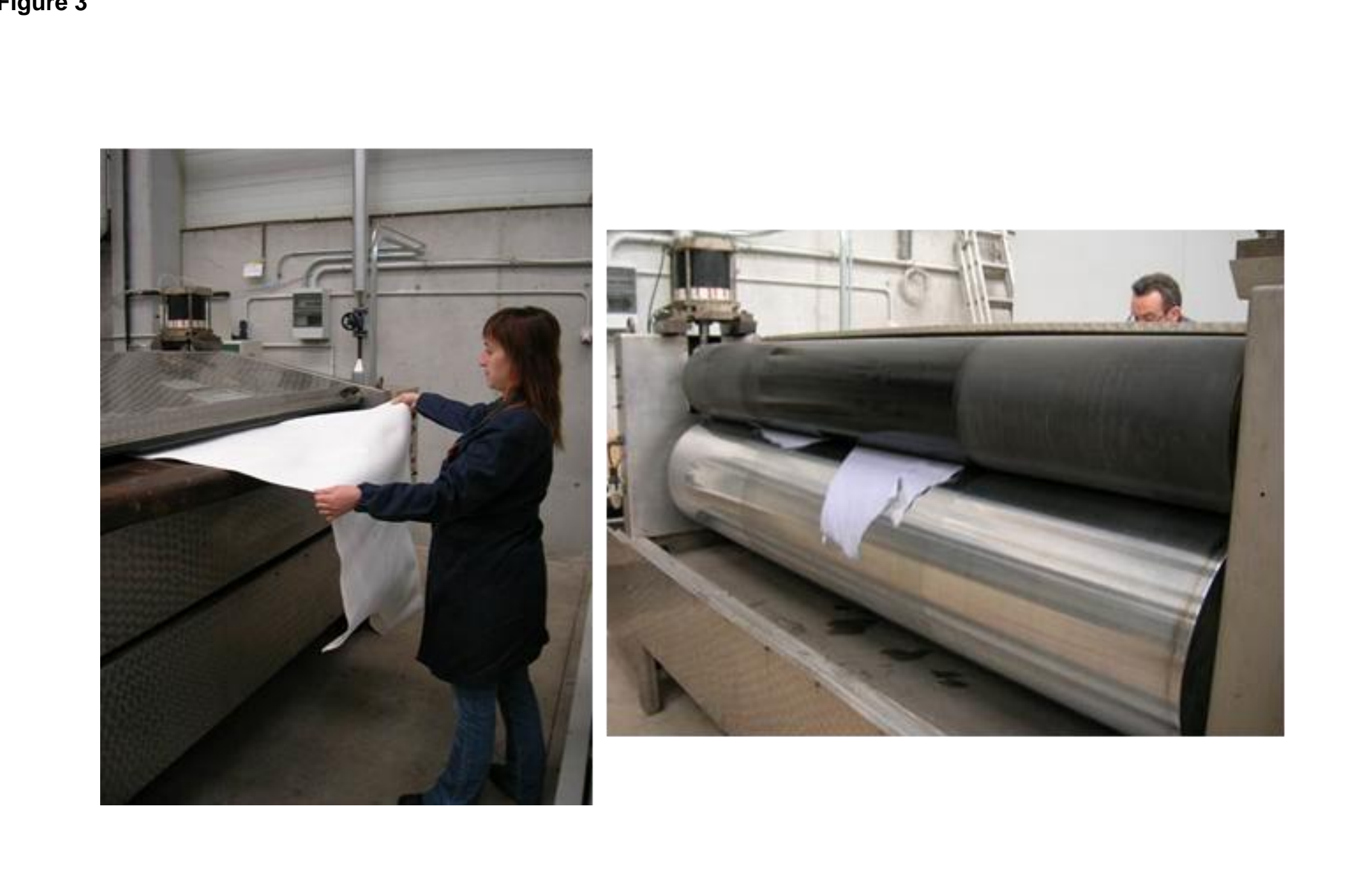

Figure 3

\section{3}
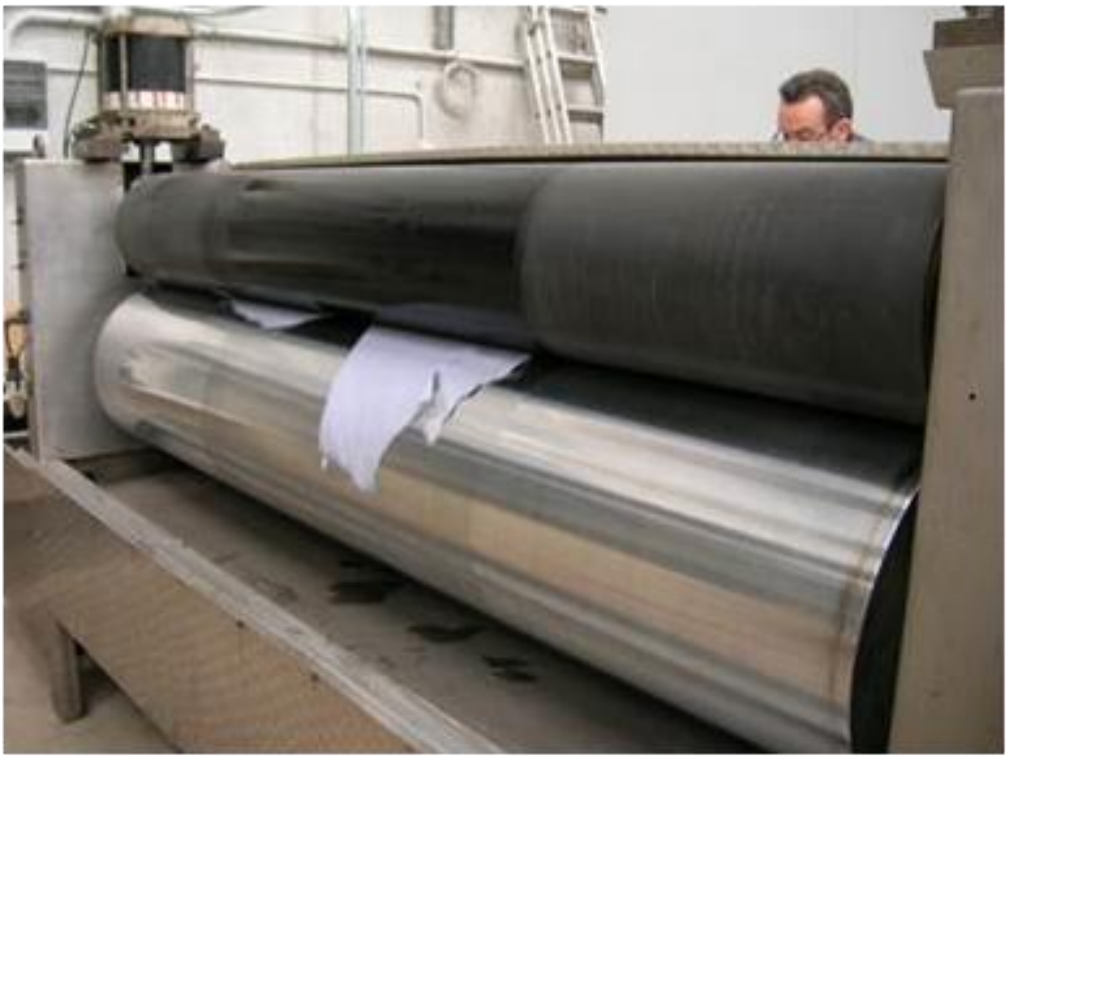

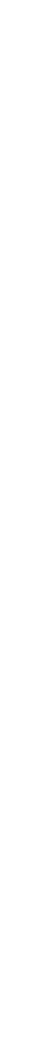

.
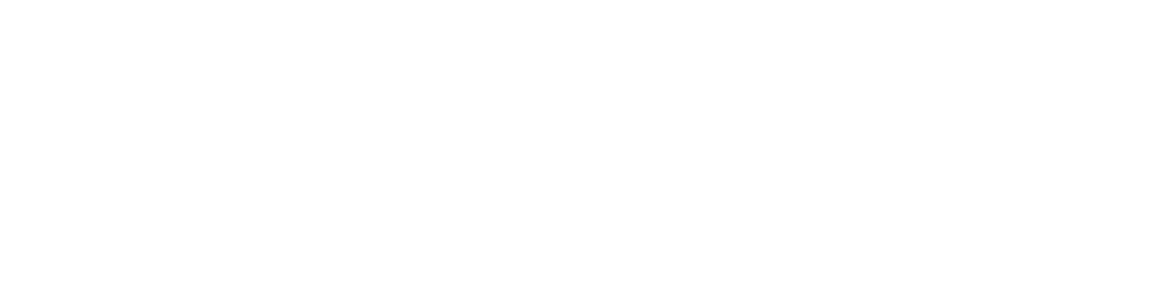

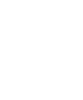




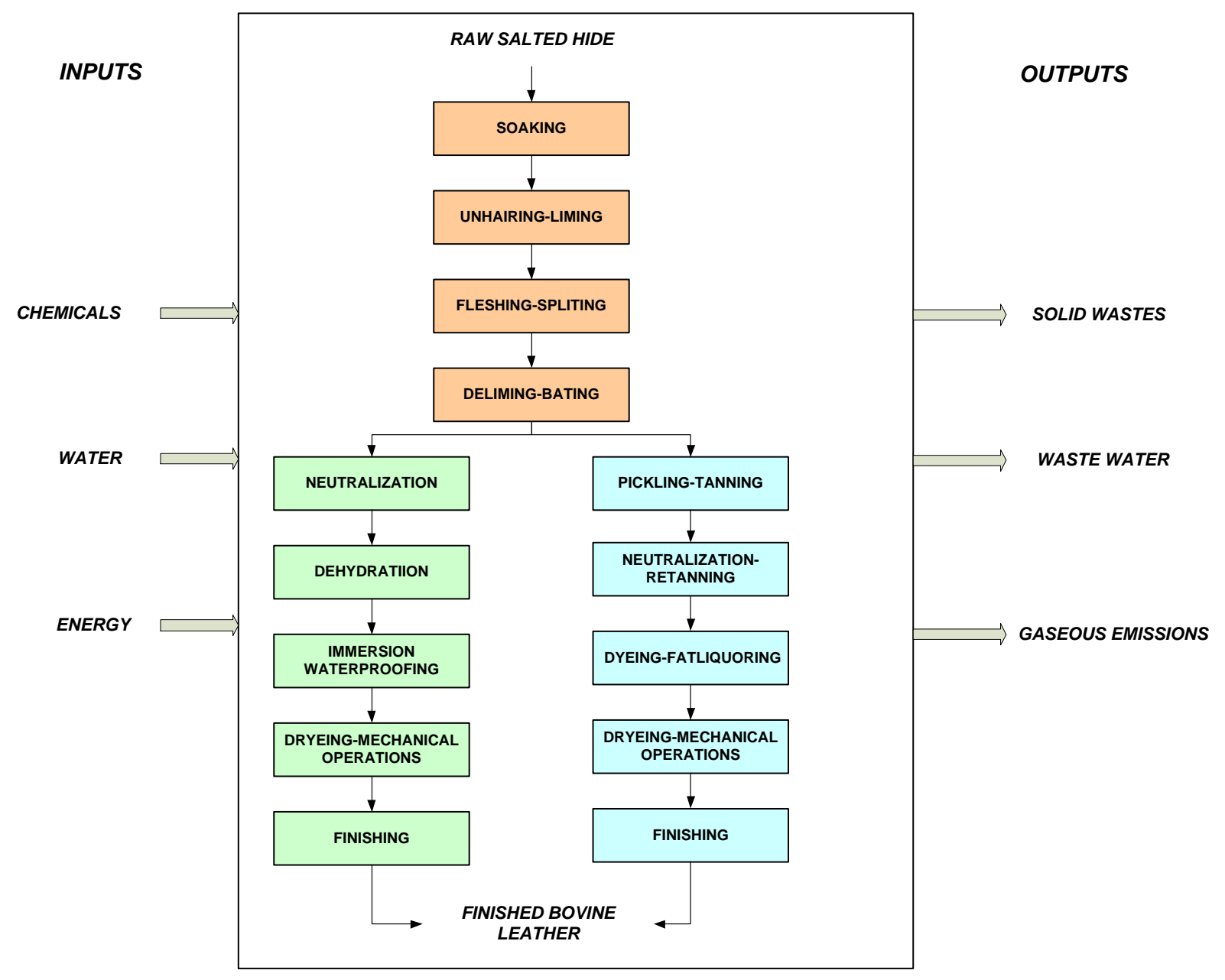


Figure 5

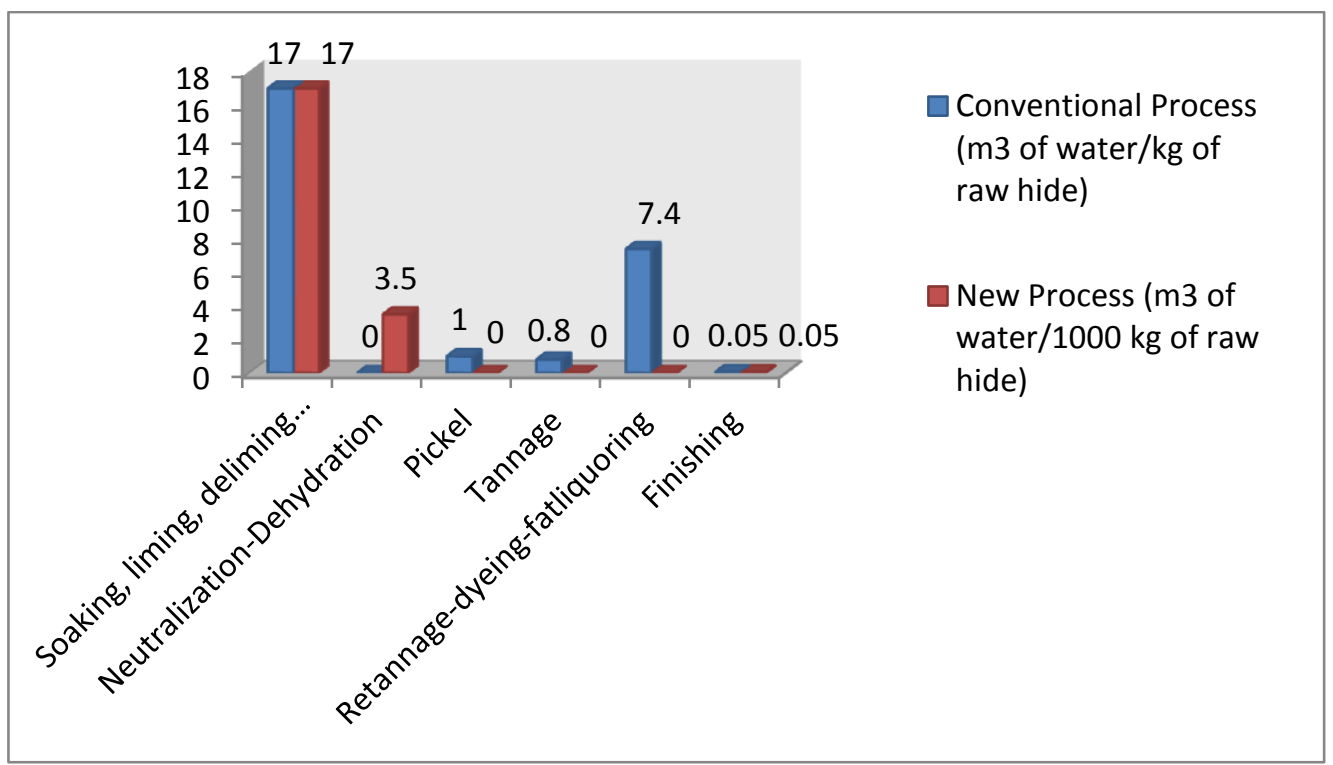


Figure 6

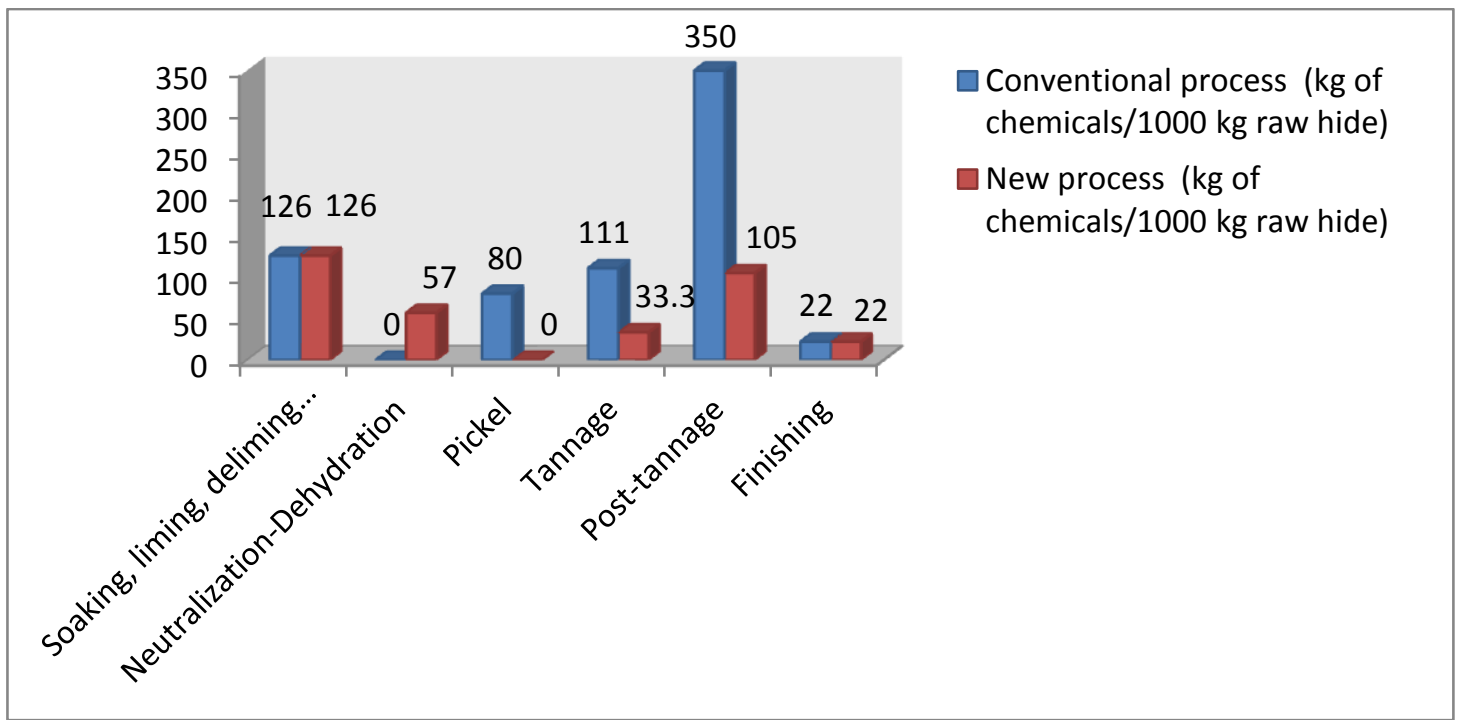


Figure 7

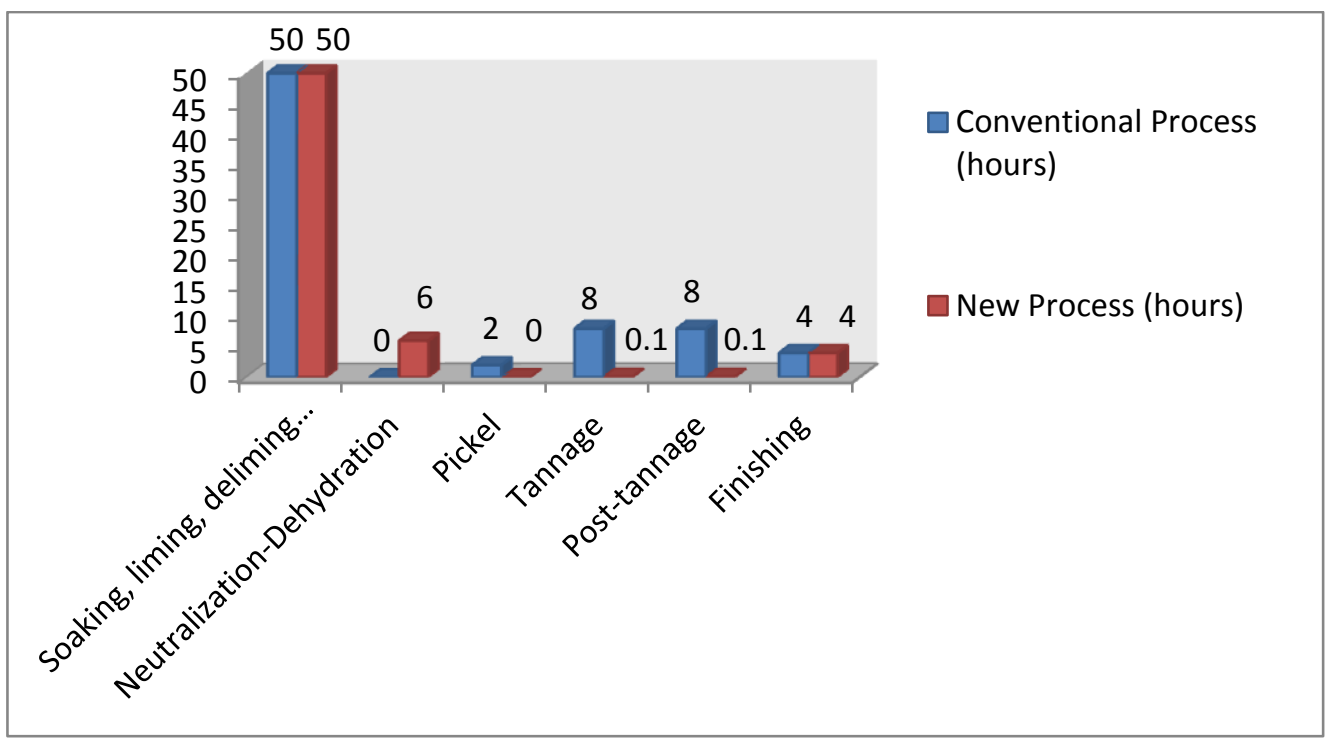


Figure 8

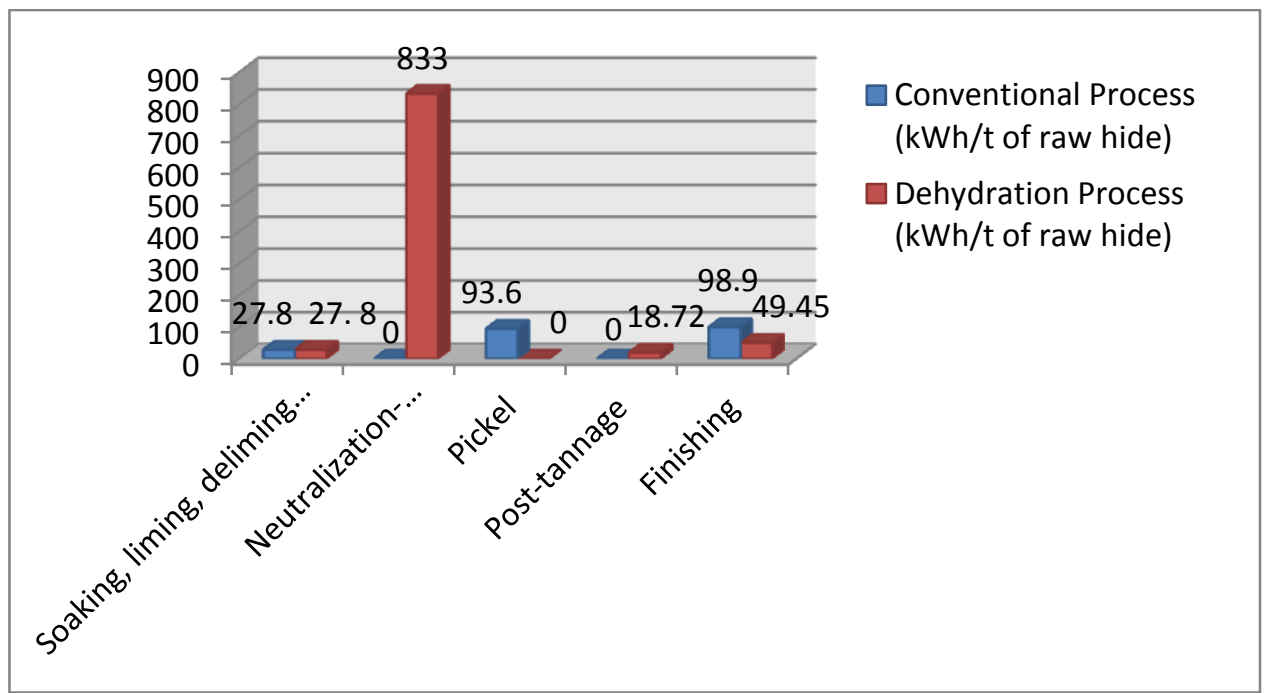


Figure 9

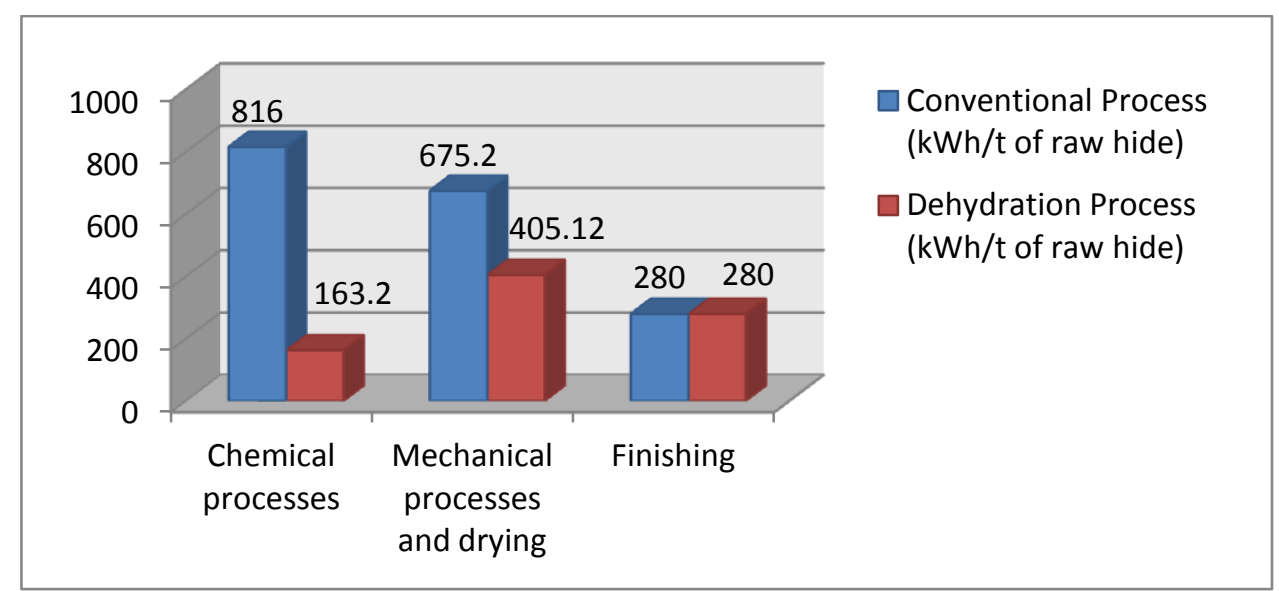


Figure 10

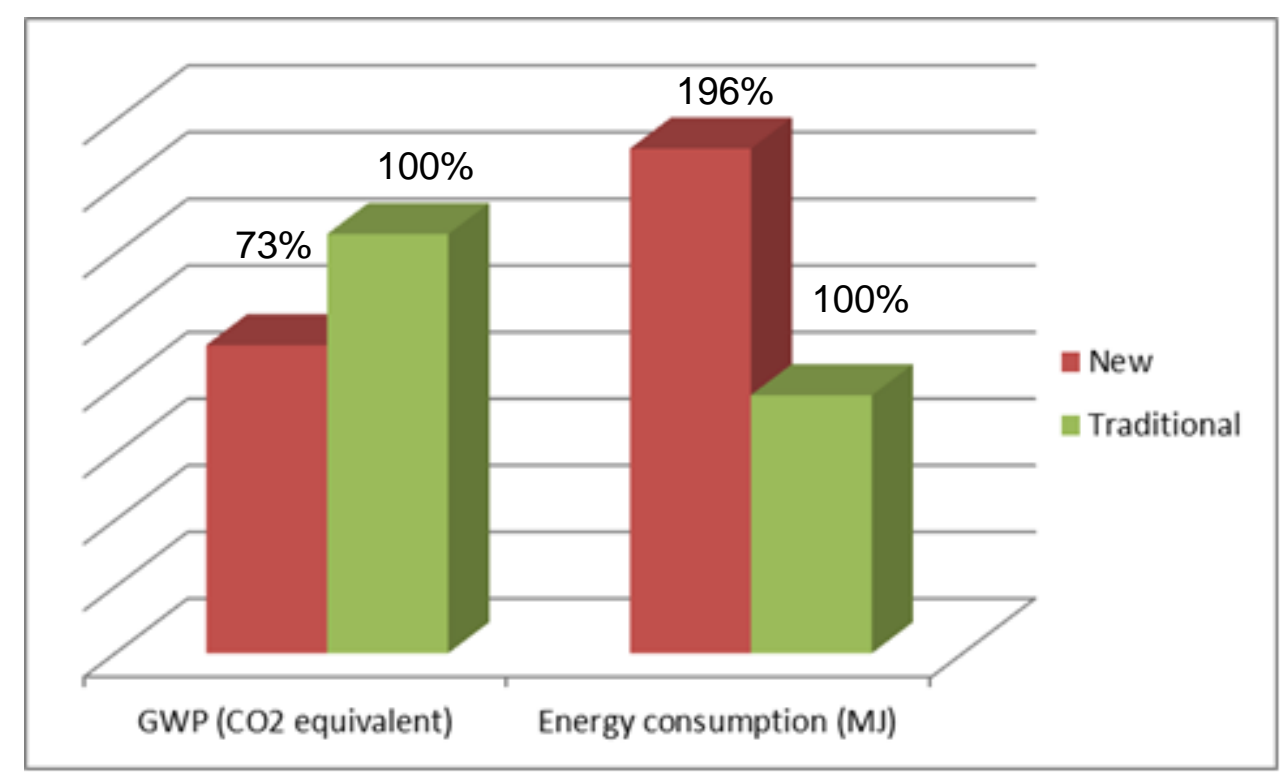

$$
\text { GWP (CO2 equivalent) Energy consumption (MJ) }
$$


Figure 12

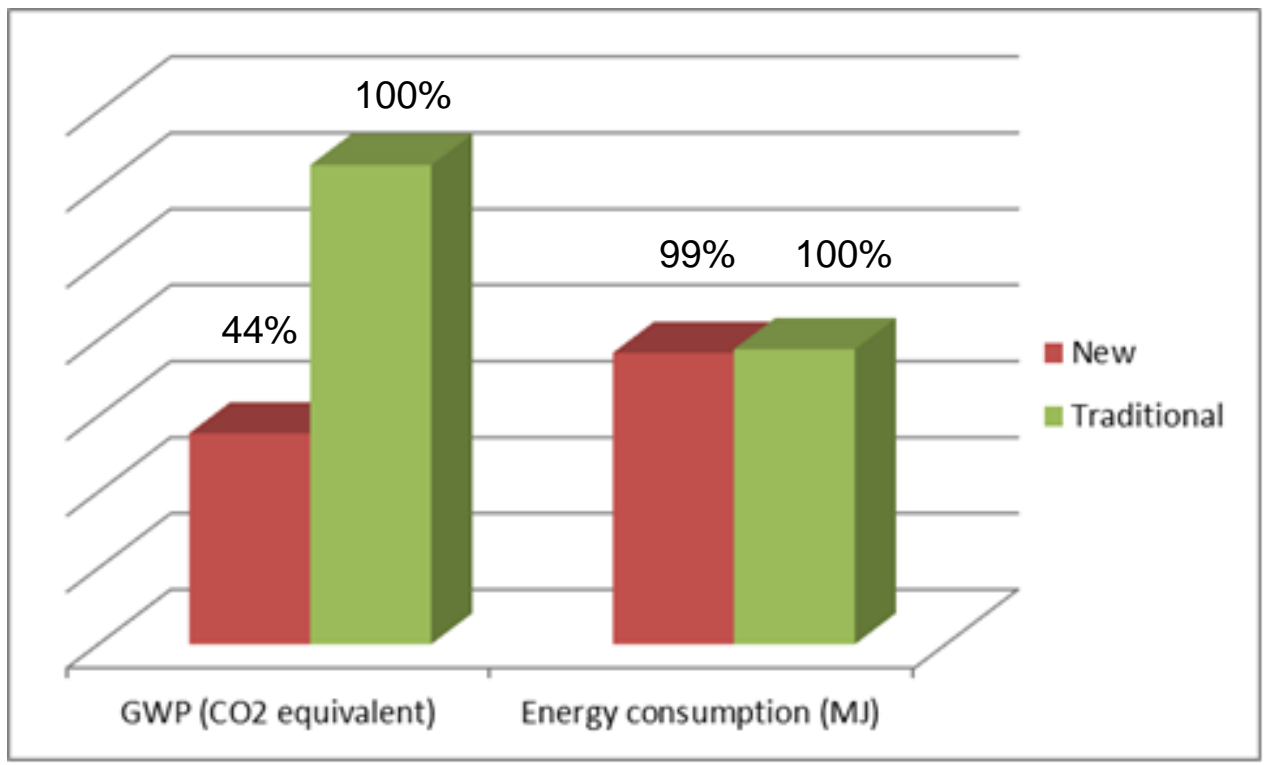

$$
\text { GWP (CO2 equivalent) Energy consumption (MJ) }
$$




\begin{tabular}{|rccc|}
\hline Float & Acetone (\%) & Time (min) & Speed (rpm) \\
\hline $\mathbf{1}$ & 200 & 60 & 15 \\
\hline & & 5 & 200 \\
\hline $\mathbf{2}$ & 200 & 60 & 15 \\
\hline & & 5 & 200 \\
\hline $\mathbf{3}$ & 200 & 60 & 15 \\
\hline & & 5 & 200 \\
\hline $\mathbf{4}$ & 200 & 60 & 15 \\
\hline & & 5 & 600 \\
\hline
\end{tabular}

Table 1. Working parameters for bovine hides 
Table 2

\begin{tabular}{|ll|}
\hline Parameter & Conditions \\
\hline Temperature & $25^{\circ} \mathrm{C}$ \\
\hline Drying time & $60 \mathrm{~min}$ \\
\hline Rotation speed & $25 \mathrm{rpm}$ \\
\hline Pressure & Atmospheric \\
\hline
\end{tabular}

Table 2. Drying parameters for bovine hides 


\begin{tabular}{|c|c|c|}
\hline & New System & $\begin{array}{c}\text { Traditional } \\
\text { System }\end{array}$ \\
\hline Tensile strength $(\mathrm{N})$ & 200.9 & 146.5 \\
\hline Tear load (N/mm) & 71.6 & 34.3 \\
\hline Distension of grain (mm) & 10.8 & 11.2 \\
\hline Strength of grain $(\mathrm{kg})$ & 25.2 & 23.2 \\
\hline Shrinkage temperature $\left({ }^{\circ} \mathrm{C}\right)$ & 93 & 108 \\
\hline Flex resistance (\#cycles) & 100000 & 100000 \\
\hline Dry rub fastness (100 cycles) & $3-4$ & $3-4$ \\
\hline Wet rub fastness ( 25 cycles) & $3-4$ & $3-4$ \\
\hline Dry adhesion (N/cm) & 23.5 & 23.9 \\
\hline $\begin{array}{lcccc}\text { Determination of matter soluble in } & \text { ichloromethane }(\%) & & & \\
\text { dichlo } & & & \end{array}$ & 11.6 & 10.7 \\
\hline Water soluble organic matter $(\%)$ & 0.5 & 0.5 \\
\hline Water soluble inorganic matter (\%) & 0.9 & 1.0 \\
\hline Chromium oxide content (\%) & 3.0 & 3.2 \\
\hline Determination of $\mathrm{pH}$ & 3.7 & 3.5 \\
\hline
\end{tabular}

Table 3. Physical and Chemical Tests 
Click here to download Data File: List of abbreviations.docx (

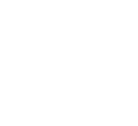

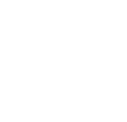
(1) (1) (1) (1)

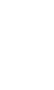
(2) (1) . .

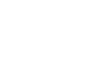

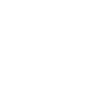

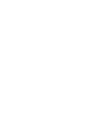
.

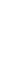
. (1) . . .

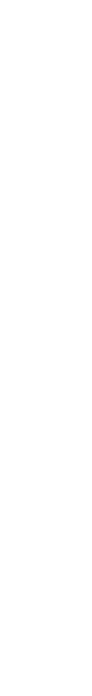
( (

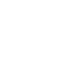

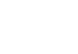

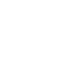

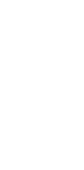

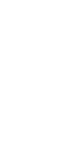

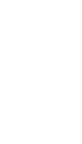
(

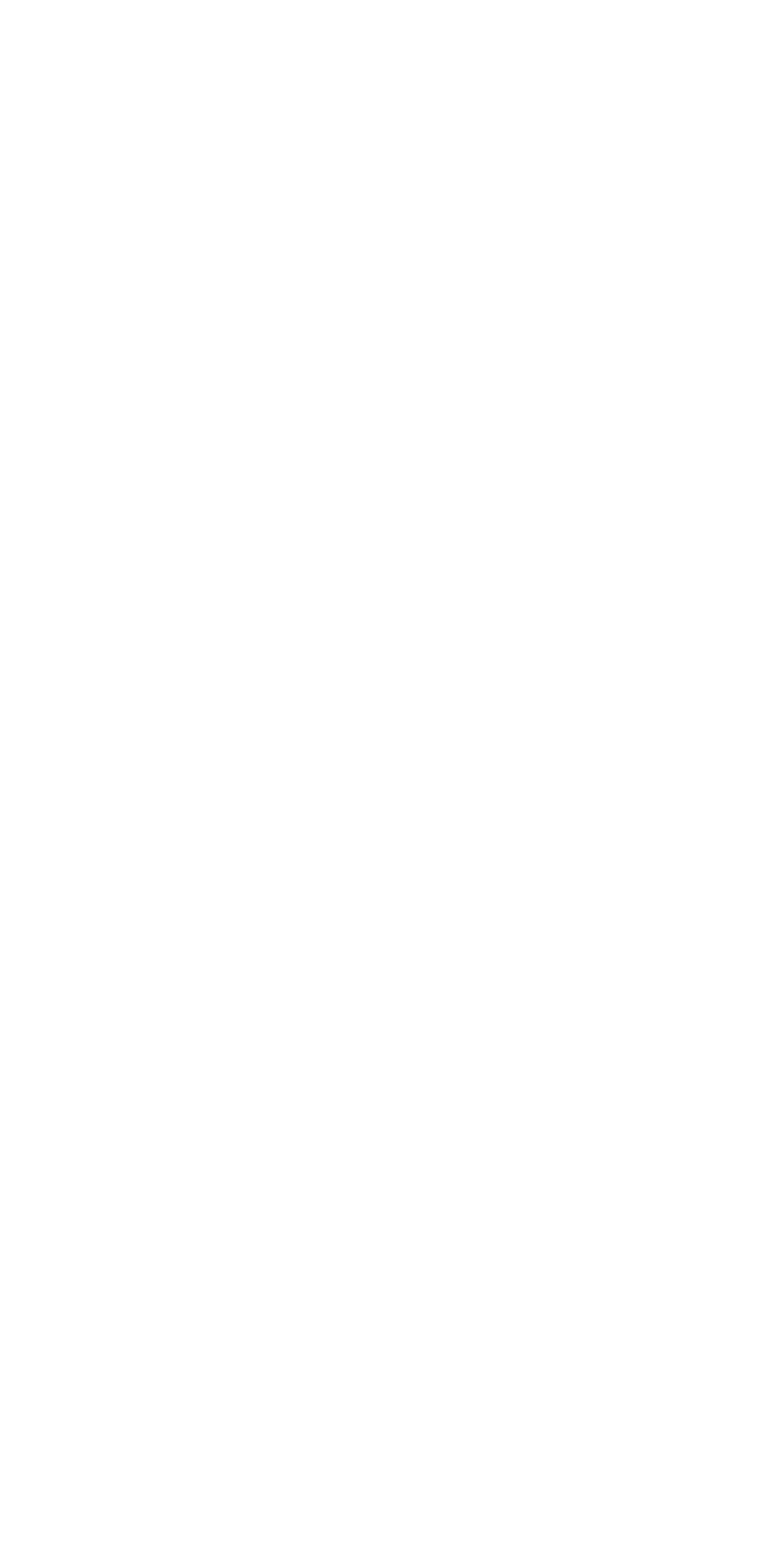


List of captions
Click here to download Data File: List of figure captions.docx Click here to download Data File: List of figure captions.docx

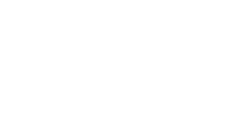

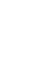

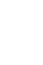

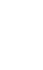

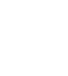
(1) (1) (1) (1)

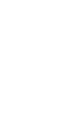

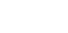
(1) (1) (1) (1) (1) . . . . . . . . . . . . 
Figure $1 \mathrm{~B} / \mathrm{W}$
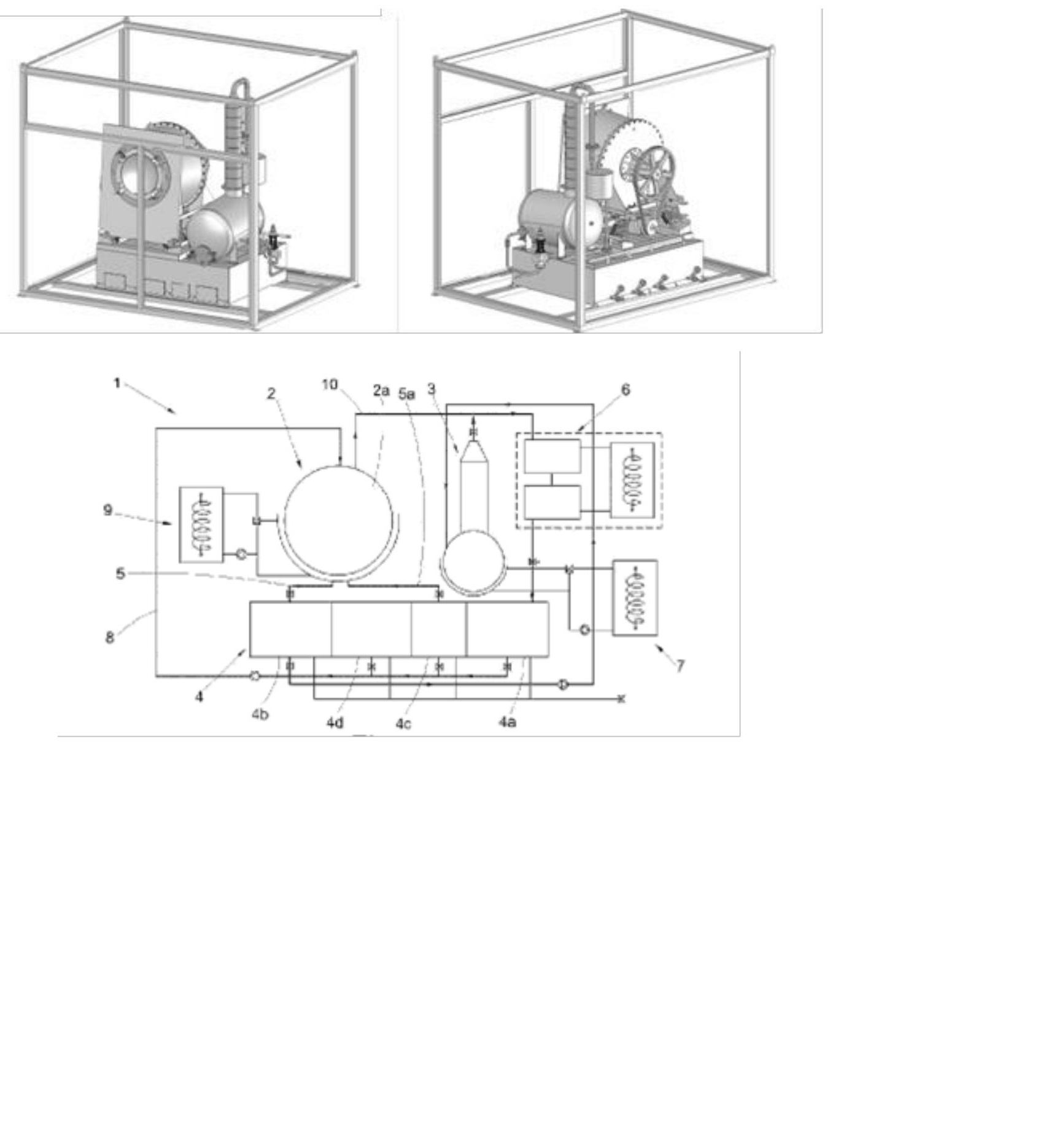


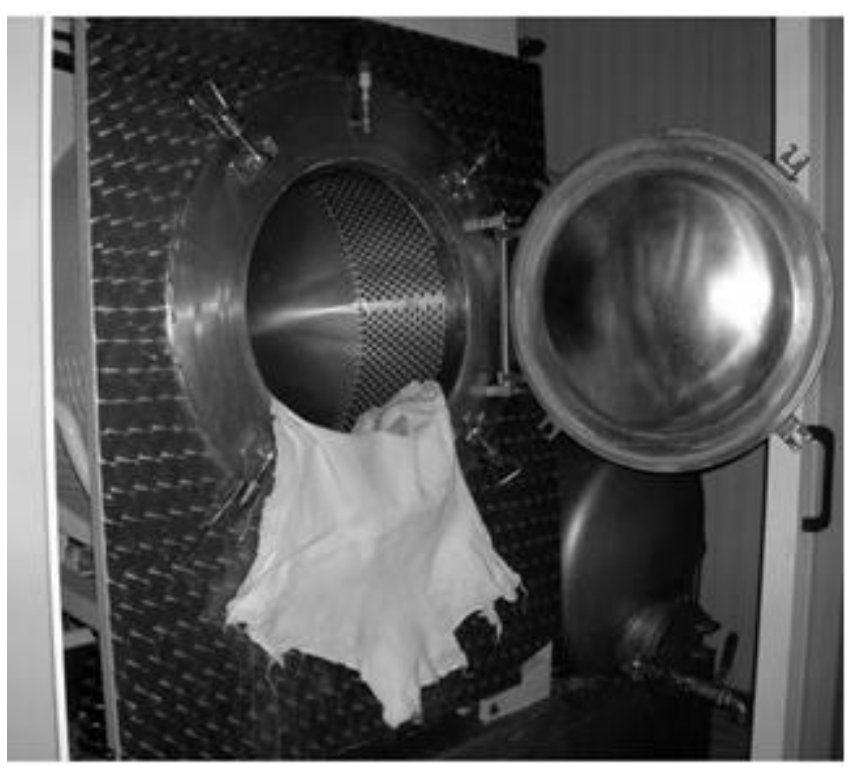



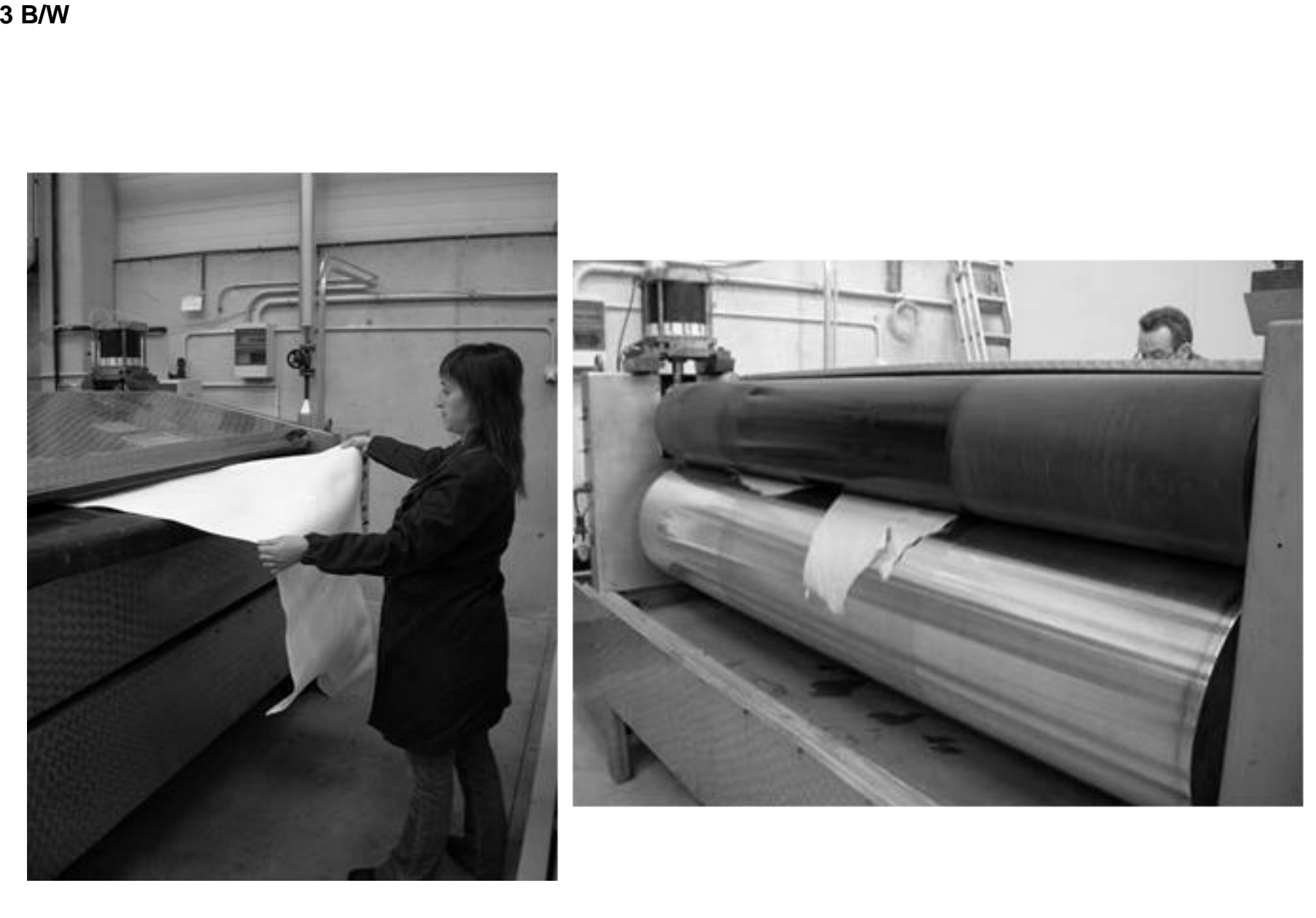

Figure $3 \mathrm{~B} / \mathrm{W}$
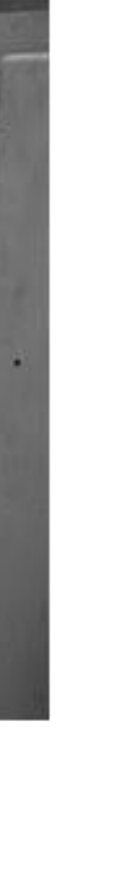

Figure 3 B/W

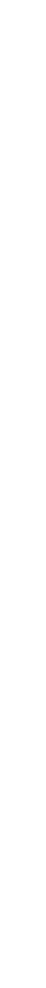




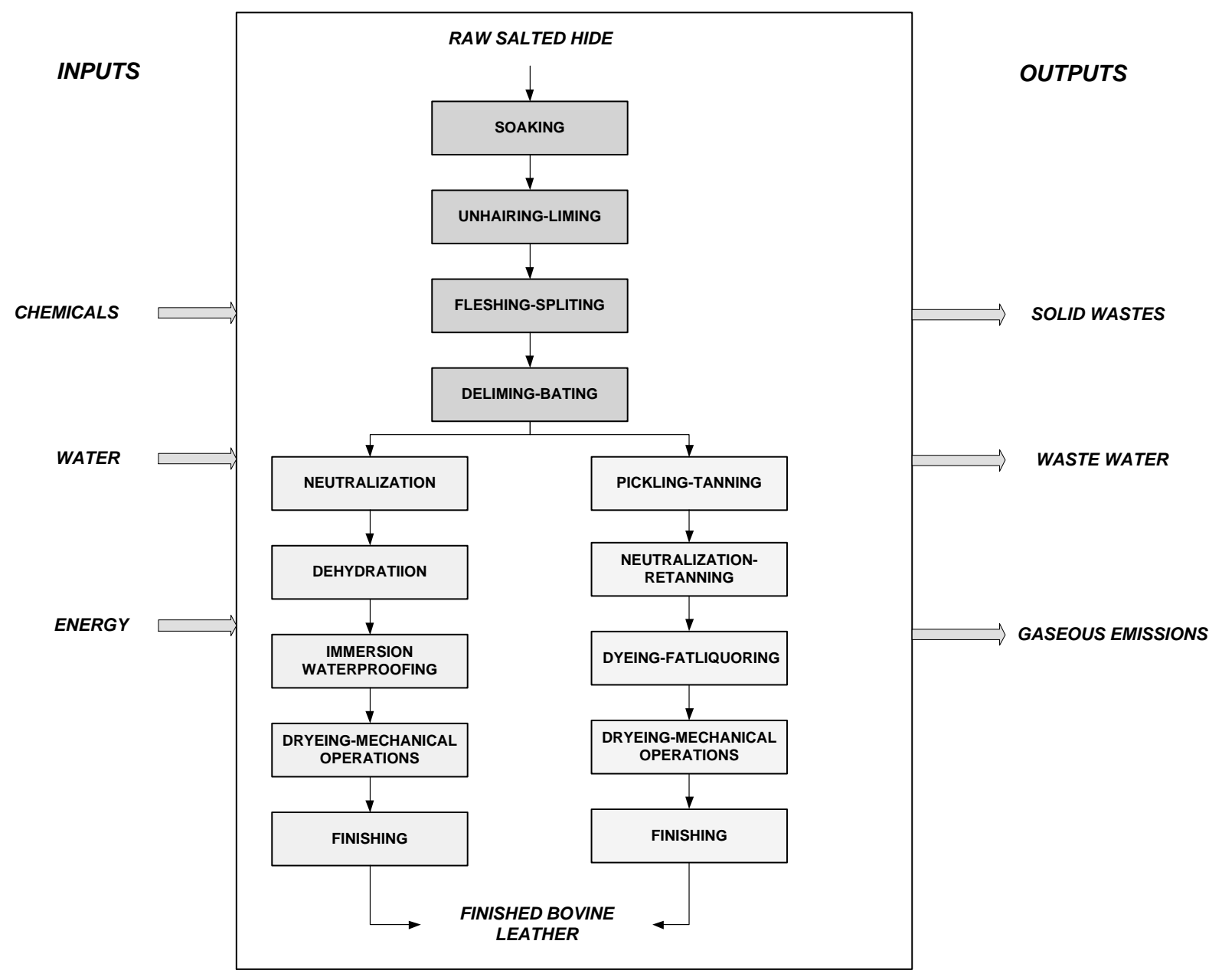


Figure $5 \mathrm{~B} / \mathrm{W}$

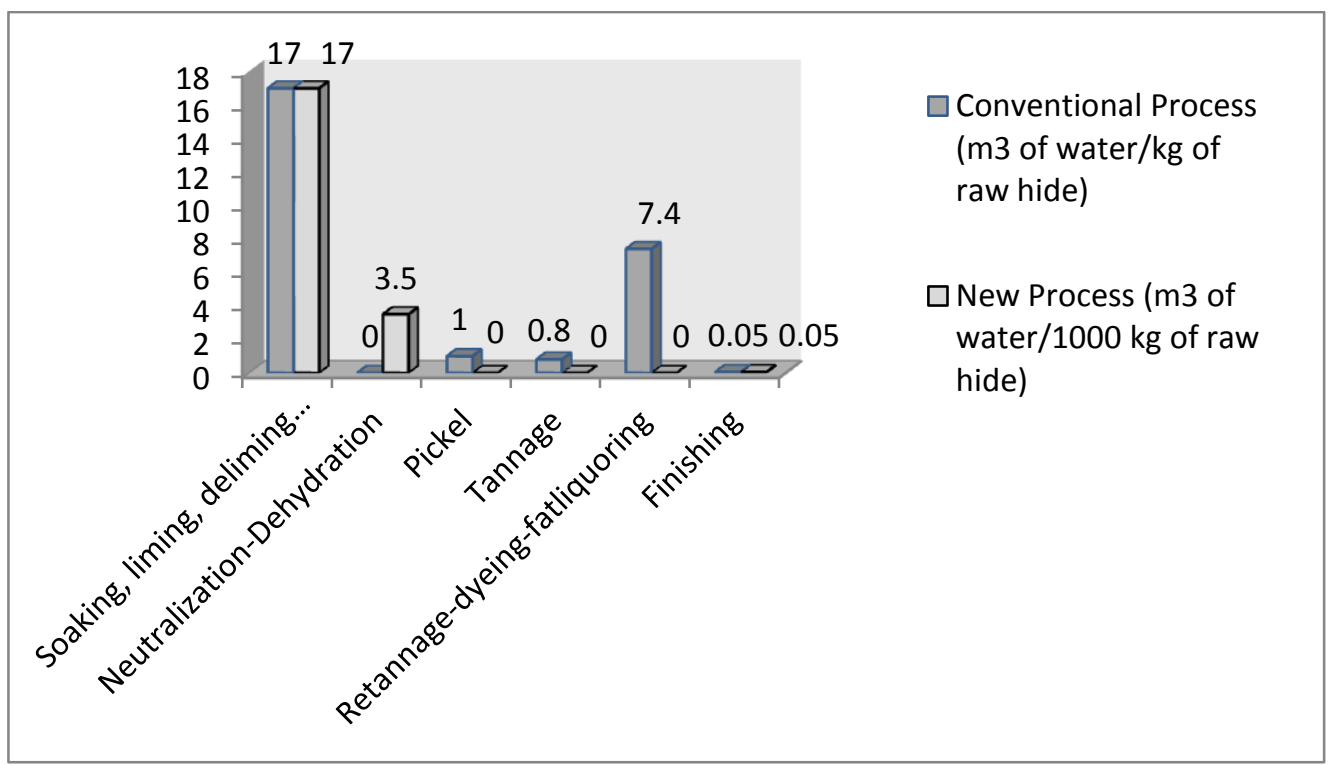


Figure $6 \mathrm{~B} / \mathrm{W}$

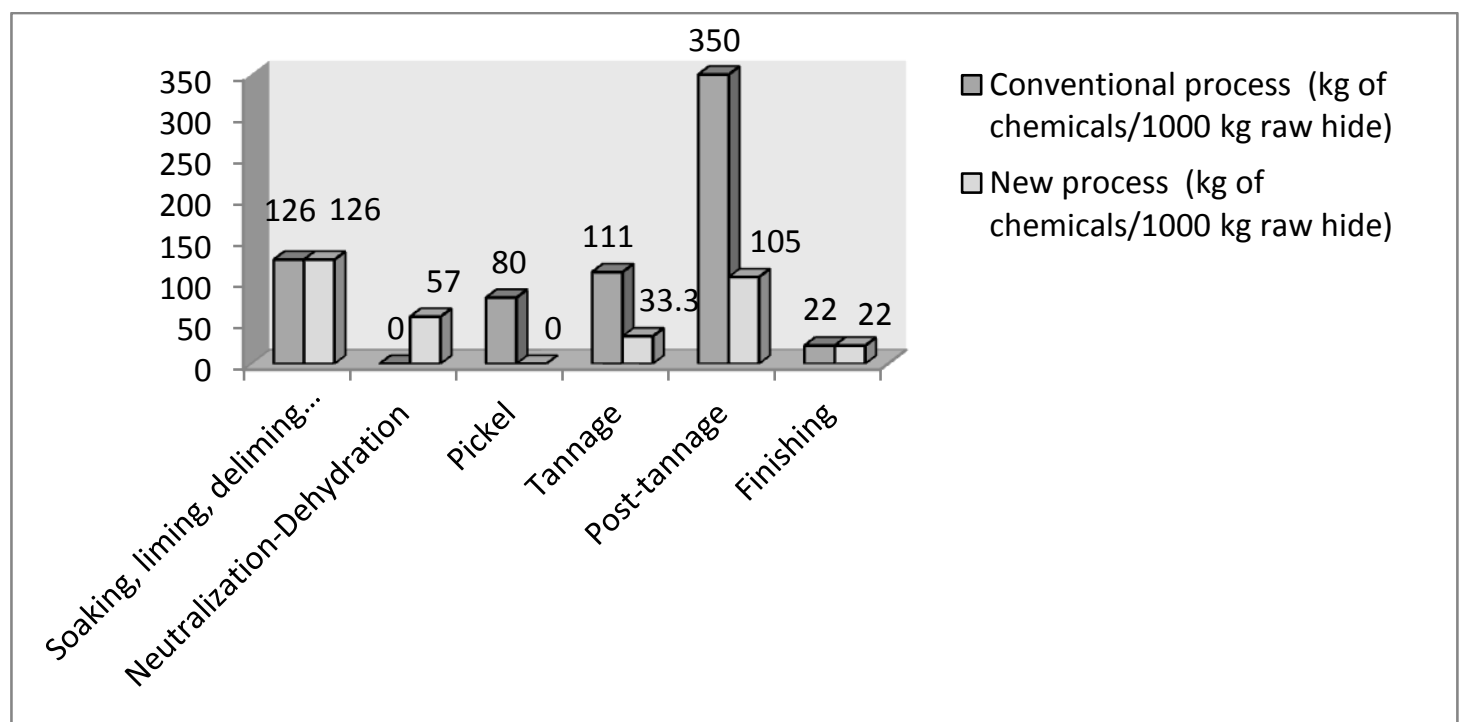




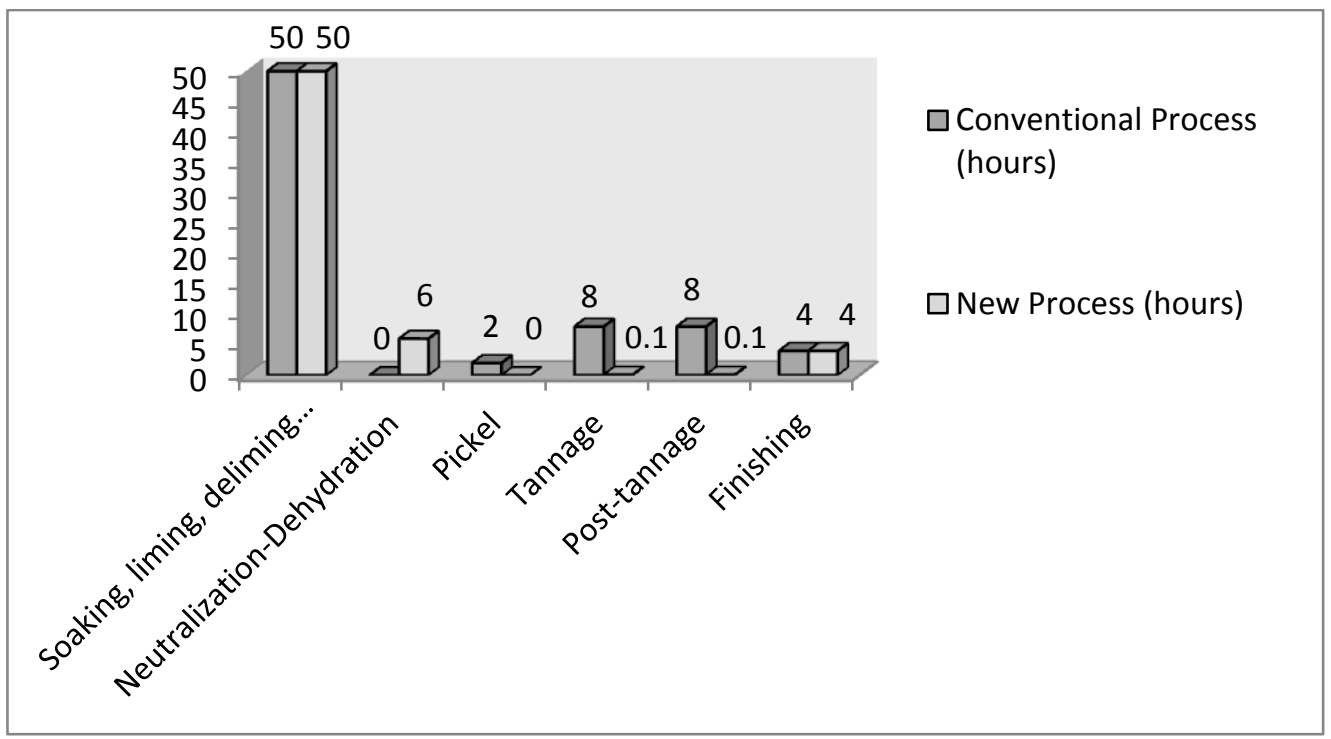


Figure $8 \mathrm{~B} / \mathrm{W}$

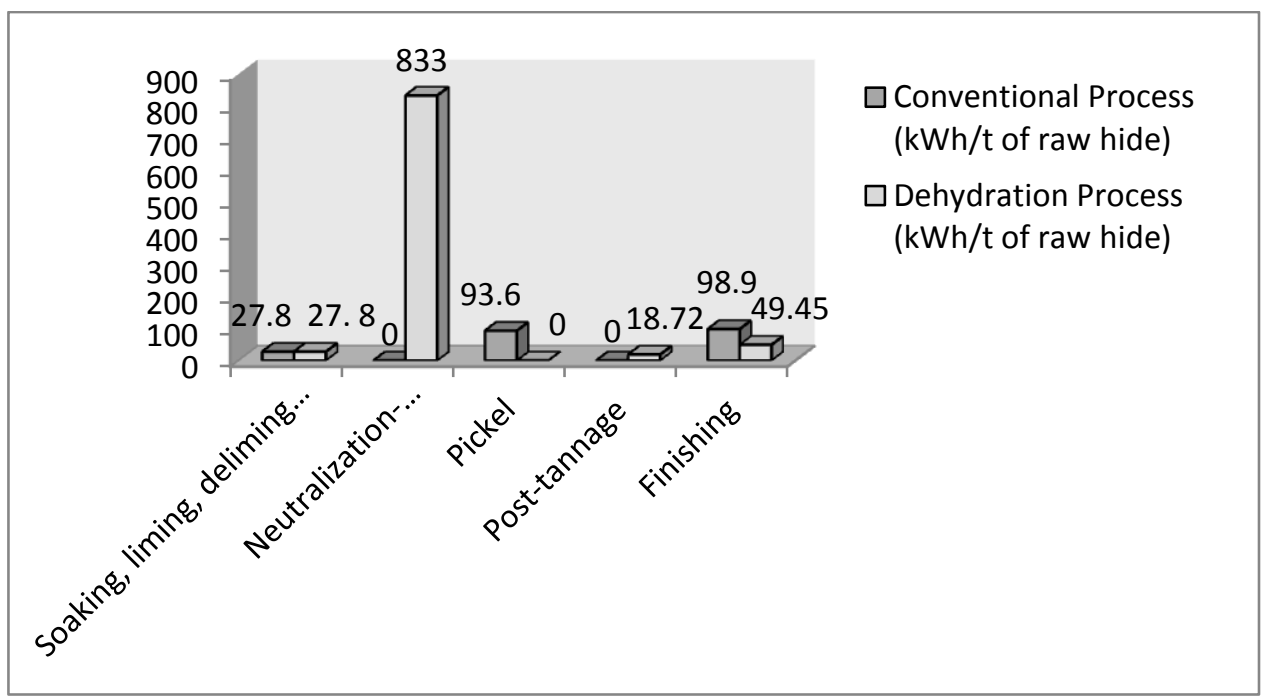


Figure $9 \mathrm{~B} / \mathrm{W}$

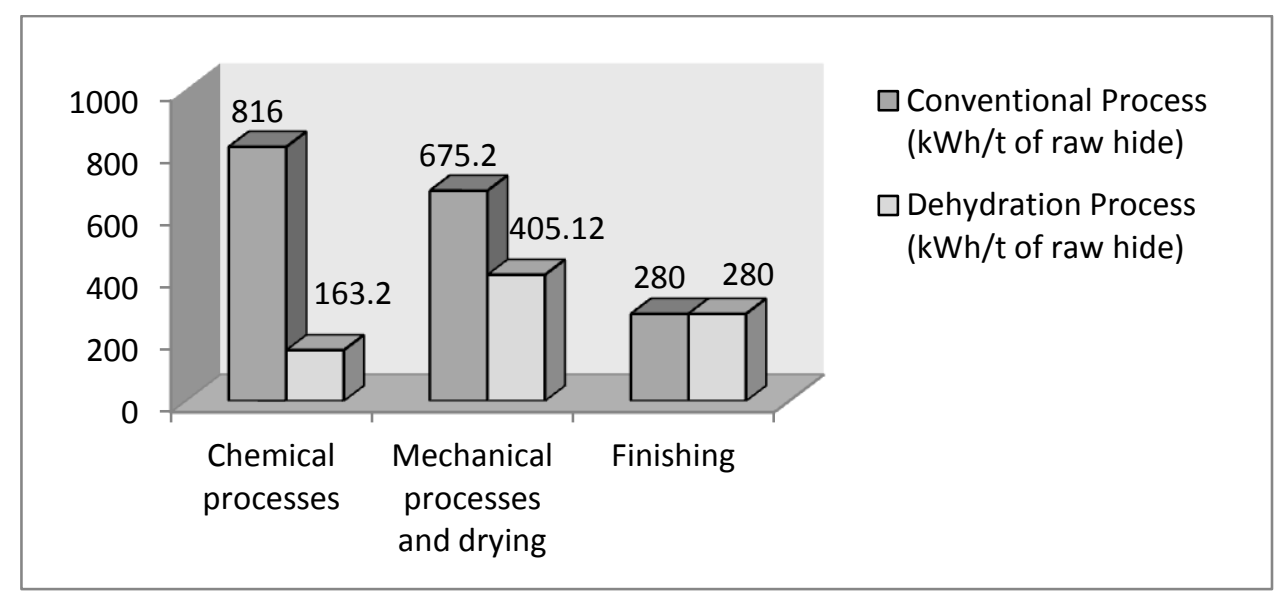


Figure $10 \mathrm{~B} / \mathrm{W}$

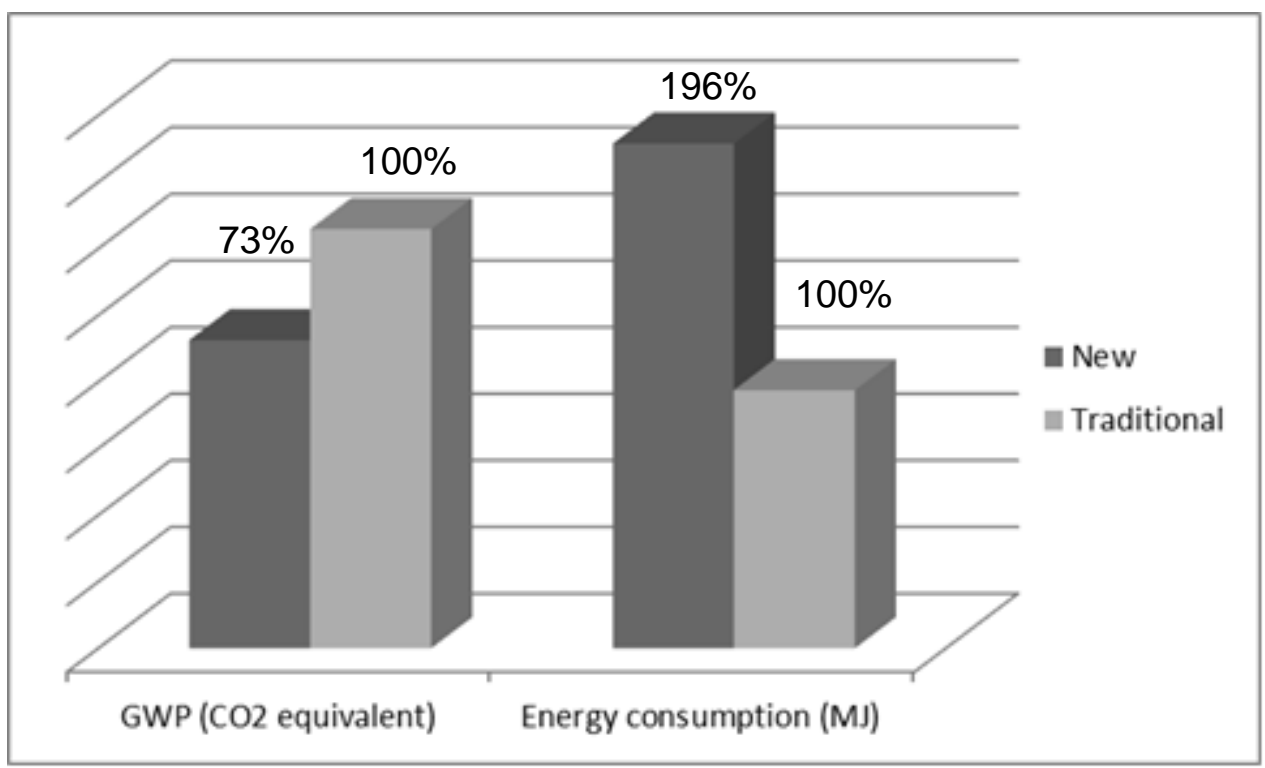

$$
\text { GWP (CO2 equivalent) Energy consumption (MJ) }
$$


Figure $11 \mathrm{~B} / \mathrm{W}$

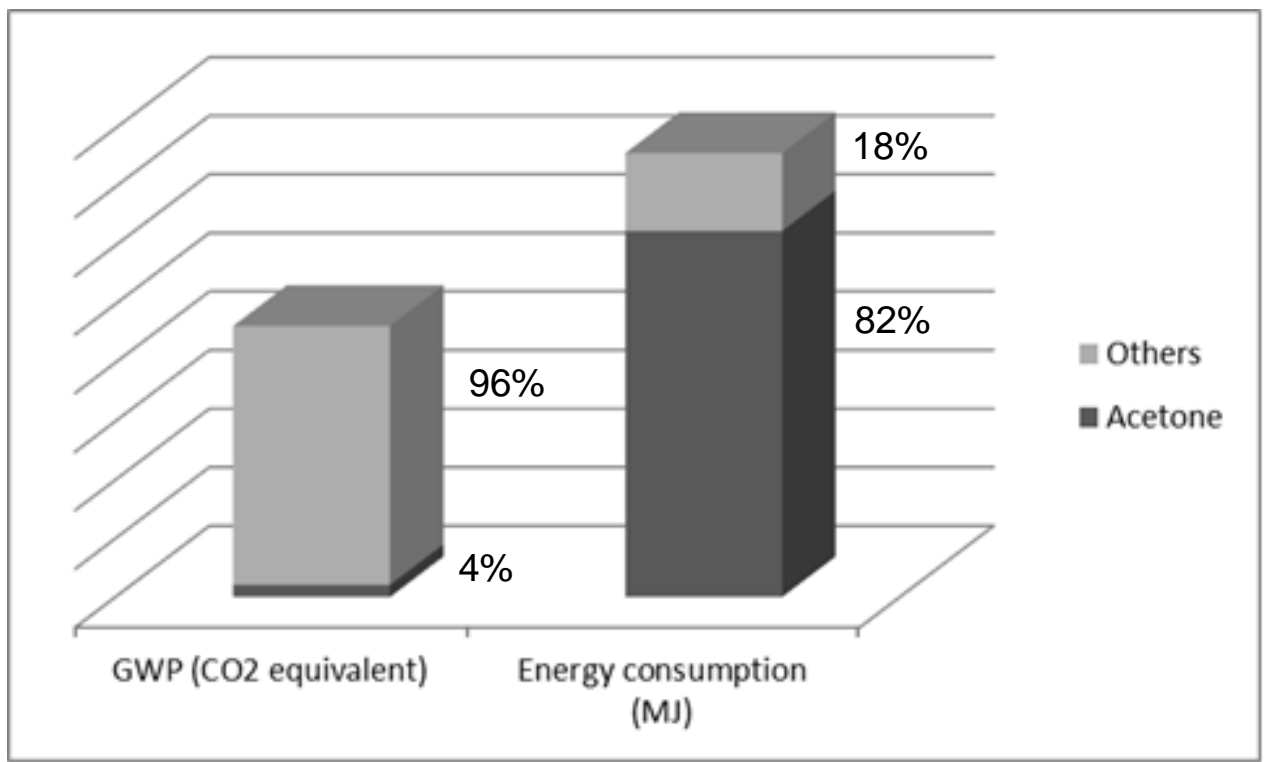

(MJ) 
Figure $12 \mathrm{~B} / \mathrm{W}$

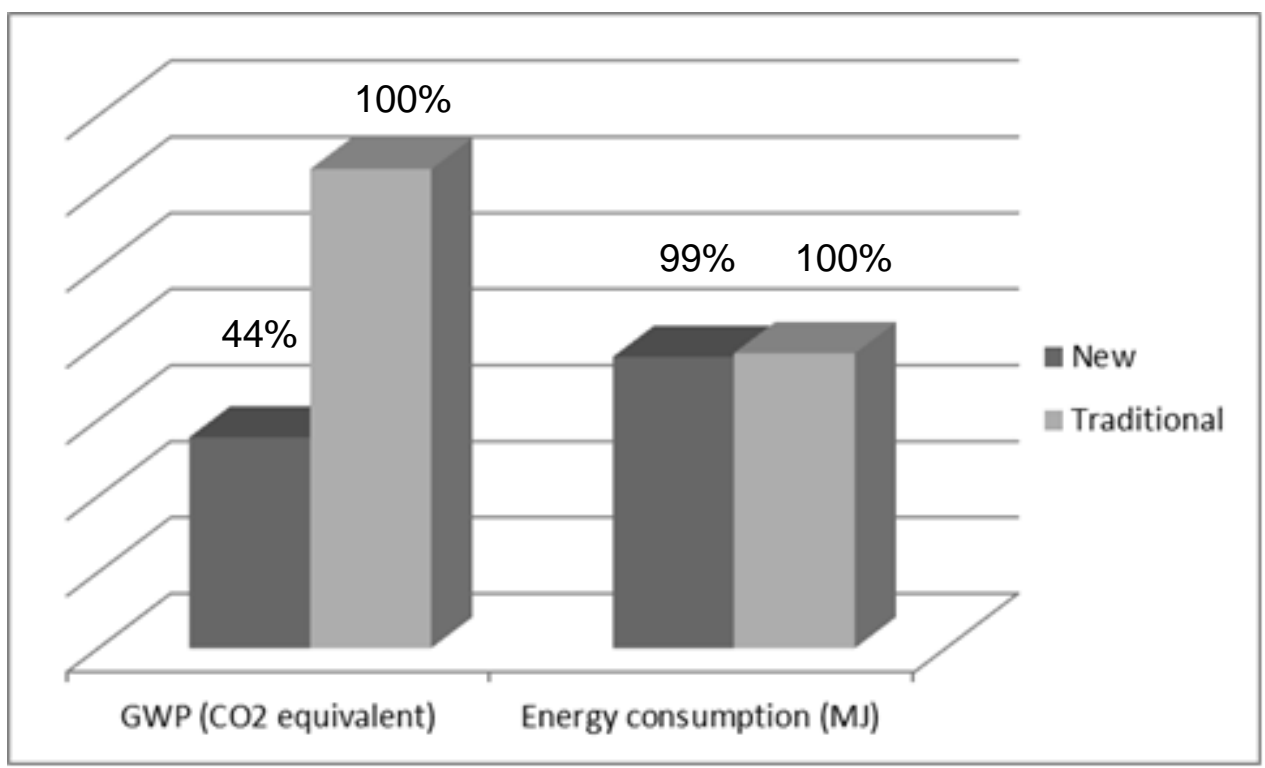

$$
\text { GWP (CO2 equivalent) Energy consumption (MJ) }
$$

